University of Louisville

ThinkIR: The University of Louisville's Institutional Repository

Electronic Theses and Dissertations

$5-2014$

\title{
The performance of the $\mathrm{K} 6$ scale in a large adolescent sample.
}

Nicholas Chalmer Peiper 1982-

University of Louisville

Follow this and additional works at: https://ir.library.louisville.edu/etd

Part of the Epidemiology Commons

\section{Recommended Citation}

Peiper, Nicholas Chalmer 1982-, "The performance of the K6 scale in a large adolescent sample." (2014). Electronic Theses and Dissertations. Paper 1109.

https://doi.org/10.18297/etd/1109

This Doctoral Dissertation is brought to you for free and open access by ThinkIR: The University of Louisville's Institutional Repository. It has been accepted for inclusion in Electronic Theses and Dissertations by an authorized administrator of ThinkIR: The University of Louisville's Institutional Repository. This title appears here courtesy of the author, who has retained all other copyrights. For more information, please contact thinkir@louisville.edu. 
THE PERFORMANCE OF THE K6 SCALE IN A LARGE ADOLESCENT SAMPLE

By

Nicholas Chalmer Peiper

B.A., Transylvania University, 2004

M.P.H., University of Kentucky, 2006

\begin{abstract}
A Dissertation
Submitted to the Faculty of the

School of Public Health and Information Sciences of the University of Louisville in Partial Fulfillment of the Requirements

for the Degree of
\end{abstract}

Doctor of Philosophy

Department of Epidemiology and Population Health

University of Louisville

Louisville, Kentucky

May 2014 


\section{Copyright 2013 by Nicholas Chalmer Peiper}

All rights reserved 

Nicholas Chalmer Peiper

B.A., Transylvania University, 2004

M.P.H., University of Kentucky, 2006

A Dissertation Approved on

December 6, 2013

by the following Dissertation Committee:

Carlton Hornung, Dissertation Chair

Richard Baumgartner, Dissertation Co-Chair

Richard Kerber, Committee Member

Liz O’Brien, Comittee Member

Robert Illback, Committee Member

Richard Clayton, Committee Member

Richard Wilson, Committee Member 


\section{ACKNOWLEDGMENTS}

I would like to thank my faculty mentor, Dr. Carlton Hornung, for his guidance throughout my academic tenure. I would also like to thank the research team at REACH Evaluation for their invaluable and timely support. In particular, I am forever grateful for the unconditional support Dr. Robert Illback and his family has shown me during my time at REACH Evaluation. Many thanks to Dr. Richard Clayton for continuing to espouse my professional development. Lastly, I thank Connie Smith, Steve Cambron, and the members of the Kentucky State Epidemiologic Outcomes Workgroup for their hard work and collaborative impact.

Funding for this study was provided by the State Epidemiologic Outcomes Workgroup Contract HHSS28320070048I/HHSS28300001T and the Strategic Prevention Framework - Partnerships for Success II Grant SP019436 through the Center for Substance Abuse Prevention at the Substance Abuse and Mental Health Services Administration. 


\begin{abstract}
THE PERFORMANCE OF THE K6 SCALE IN A LARGE ADOLESCENT SAMPLE Nicholas C. Peiper

December 6, 2013

This dissertation is an applied research study to examine the performance of the K6 scale that measures serious emotional disturbance (SED) among adolescents. As the K6 was included in the 2012 administration of the Kentucky Incentives for Prevention Survey (KIP), three specific aims are included: 1) confirm the unidimensional structure of the K6 among adolescents using factor analysis; 2) define the prevalence and correlates of adolescent SED among Kentucky students; and 3) utilize latent class analysis (LCA) to empirically derive clinically relevant subtypes of adolescents with SED.
\end{abstract}

Of the 122,718 students who completed the KIP in 2012, approximately $89 \%$ provided complete data for the K6 $(n=108,736)$. Both principal axis and confirmatory factor analysis supported the unidimensional structure of the K6. Using the unweighted scoring algorithm (i.e., 13+) to screen for SED, the 30-day prevalence for Kentucky was $13.9 \%$ in 2012 . Grade, gender, race/ethnicity, and family structure emerged as significant social and demographic predictors of SED. Among students with SED, the prevalence rates for substance abuse, antisocial behavior, role impairments, and peer victimization were significantly higher than those without SED. Four distinct subtypes of SED emerged from the LCA, varying by both symptom type and severity: mixed 
moderate risk, mixed high-risk, anxious moderate risk, and depressed high risk. Grade, gender, race/ethnicity, family structure, substance abuse, antisocial behavior, role impairments, and peer victimization were all significant predictors of class membership, although the magnitude of these effects were stronger for the two higher risk groups.

The next steps include validation of the K6 on other state surveys that use school and community-based samples of adolescents, generation of cross-state comparisons, and the implementation of validated statistical approaches to generate more precise SED estimates, especially when gold standard diagnoses are not available. These results indicate the K6 is particularly useful for inclusion in large epidemiologic surveys like the KIP that have limited space and logistics that demand timely administration. Thus, this dissertation provides a foundation for increased epidemiologic infrastructure in Kentucky through the timely surveillance of SED. 


\section{TABLE OF CONTENTS}

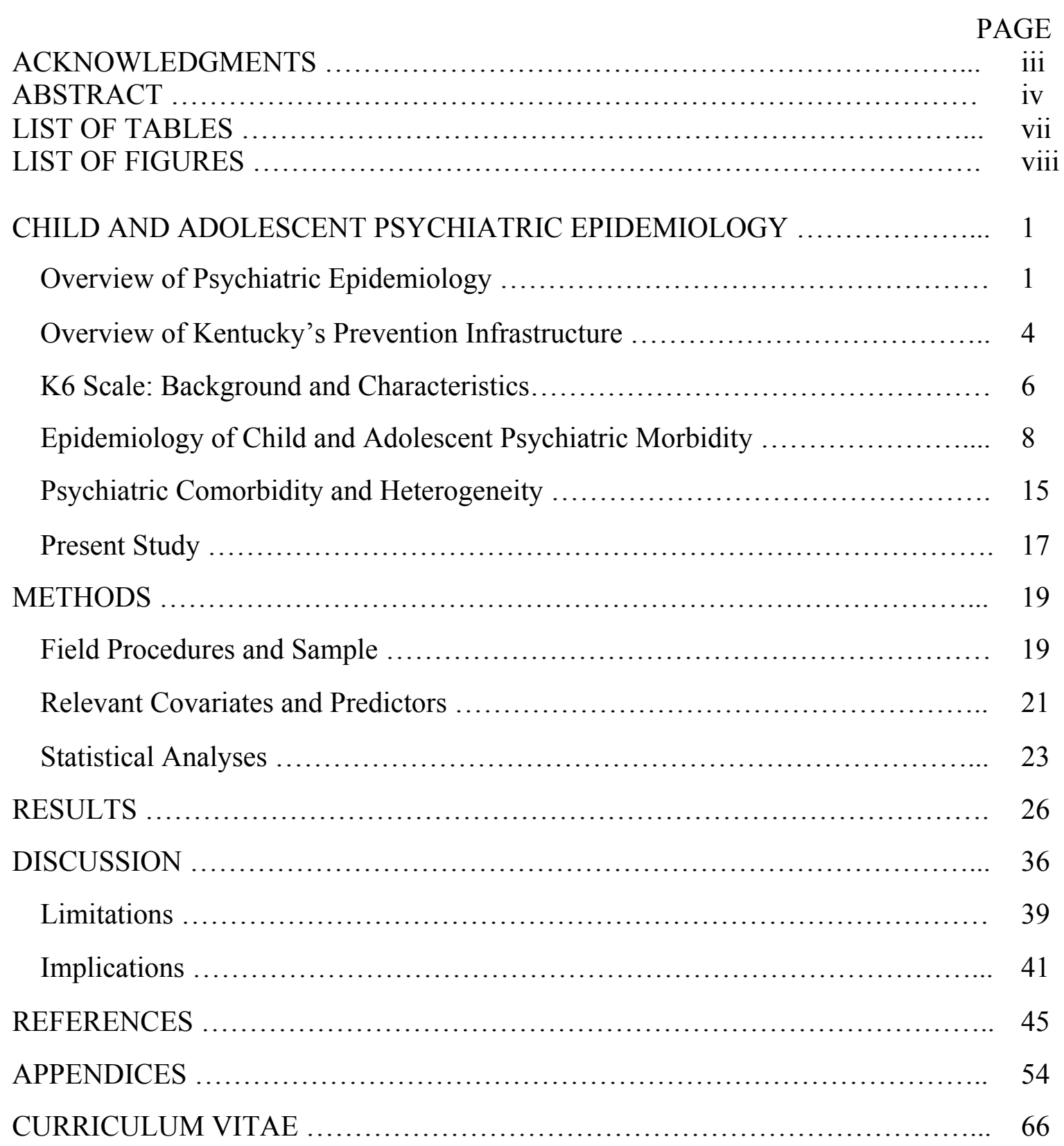




\section{LIST OF TABLES}

TABLE

PAGE

1. Social and Demographic Factors of Kentucky Students ..................... 20

2. Principal Axis Factor Analysis of the Polychoric Correlation Matrix ........... 27

3. Global Model Fit Statistics from Confirmatory Factor Analysis $\ldots \ldots \ldots \ldots \ldots \ldots \ldots .27$

4. Social and Demographic Correlates of Serious Emotional Disturbance .......... 28

5. Prevalence of Substance Abuse, Antisocial Behavior, and Role Impairments ..... 29

6. Global Model Fit Statistics from Latent Class Analysis ..................... 30

7. Social and Demographic Characteristics of Subtypes $\ldots \ldots \ldots \ldots \ldots \ldots \ldots \ldots \ldots \ldots \ldots \ldots \ldots \ldots \ldots$

8. Substance Abuse, Antisocial Behavior, and Role Impairments Among Subtypes .. 32

9. Multinomial Logistic Regression Results Predicting Class Membership .......... 33 


\section{LIST OF FIGURES}

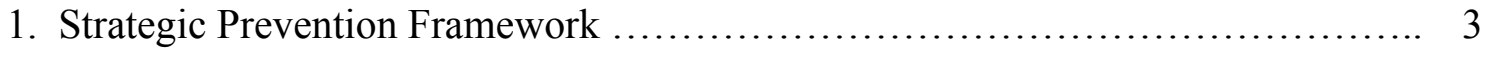

2. Substate regions including Kentucky area development districts $\ldots \ldots \ldots \ldots \ldots \ldots \ldots, 12$

3. Distribution of K6 scores .......................................... 26

4. Probability of endorsing most of the time and all of the time across subtypes ..... 30 


\section{CHAPTER I}

\section{CHILD AND ADOLESCENT PSYCHIATRIC EPIDEMIOLOGY}

\section{Overview of Psychiatric Epidemiology}

Over the past 25 years, the application of epidemiologic methods to psychiatry and clinical psychology has led to the institution of diagnostic interviews and statistical methods to estimate the incidence and prevalence of psychiatric morbidity, explore patterns of comorbidity and heterogeneity, explore clinically relevant correlates and

causal factors, improve nosology, and inform practice and policy. ${ }^{1}$ Beginning in the early 1980s, the Epidemiologic Catchment Area (ECA) Study standardized the administration of structured diagnostic interviews. ${ }^{2}$ Despite the utility and accuracy of estimates generated from these structured interviews, ${ }^{3,4}$ many community cases have been shown to have less severe psychiatric morbidity than clinical cases ${ }^{5,6}$ Public mental health policies and services have consequently shifted to making distinctions between those with severe and less severe psychiatric morbidity for resource allocation and policy planning purposes.

In 1992, US Public Law (PL) 102-321 (the Alcohol, Drug Abuse, and Mental Health Administration Reorganization Act) established a US federal Block Grant for states to fund Community Mental Health Services for adults with serious mental illness (SMI), requiring states to include incidence and prevalence estimates in their annual applications. ${ }^{7}$ The Substance Abuse and Mental Health Services Administration (SAMHSA) was also required to operationalize the definition of SMI and create an 
estimation methodology for state use. In particular, the definition of SMI set by PL 102321 required an adult to have at least one 12-month disorder defined in the Diagnostic and Statistical Manual of Mental Disorders (DSM), other than a substance use disorder, and to have serious functional impairment. ${ }^{7}$ In response to estimating the prevalence and distribution of SMI in the population for resource allocation, US federal health surveys began including measures of SMI after PL 102-321 was published.

Similarly, substance abuse prevention has also witnessed a paradigm shift during this time from individual-level interventions towards public health models that focus on individuals within the context of dynamic communities and environments. ${ }^{8,9}$ This shift has further facilitated community partnerships, capacity building, as well as the implementation and systematic evaluation of environmental strategies including policy, enforcement, and social marketing campaigns. ${ }^{8,9}$ In addition to funding Community Mental Health Services, state agencies that utilize data-driven capacity and surveillance to influence substance abuse prevention and mental health promotion have recently expanded through federal funding mechanisms. Specifically, the Center for Substance Abuse Prevention (CSAP) within SAMHSA typically funds Single State Authorities (SSA) in the form of block grants and other discretionary mechanisms. ${ }^{8,9}$ In turn, states either directly fund communities to implement the prevention practices or provide technical assistance, guidance and other supports to community organizations.

In 2004, CSAP introduced the Strategic Prevention Framework (SPF), a five-step planning and implementation model for states and communities (Figure 1). CSAP then initiated the SPF State Incentive Grant (SPF-SIG) program, funding 21 states in 2004 (Cohort I) and five states in 2005 (Cohort II). Kentucky, a Cohort I state that is 
predominantly rural and impoverished, followed the national goals of the SPF-SIG: 1) To prevent the onset and reduce the progression of substance abuse; 2) to reduce substance abused-related morbidity and mortality in communities; and 3) to build prevention capacity and infrastructure at the state and community levels. To continue and enhance the work completed within the SPF-SIG program, CSAP formally initiated the three-year State Epidemiologic Outcomes Workgroup (SEOW) program in 2010 to include mental health promotion and the prevention of mental illness as it relates to substance abuse and its consequences.

Figure 1. Strategic Prevention Framework.

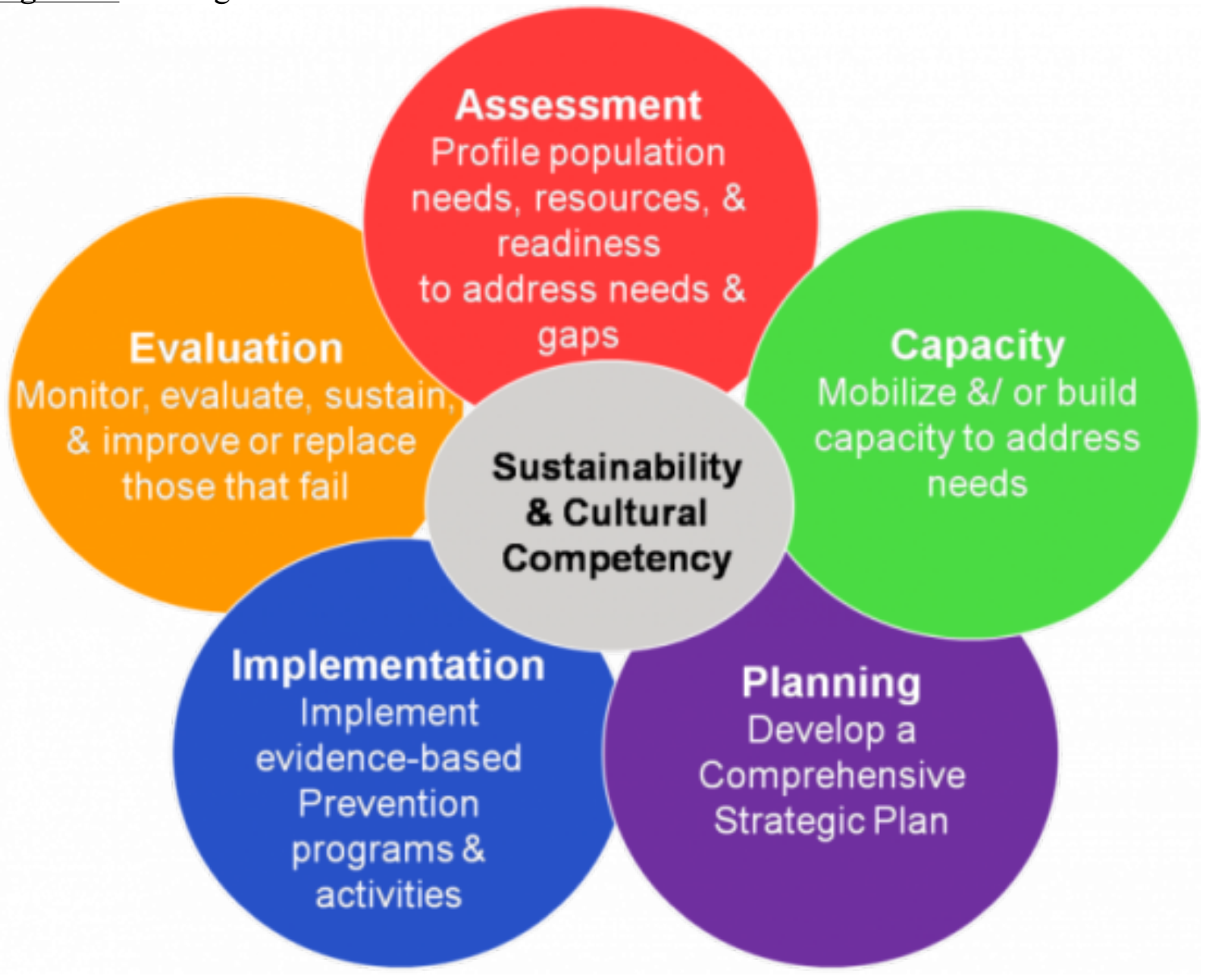




\section{Overview of Kentucky's Prevention Infrastructure}

Prior to the receipt of the $\$ 11.4$ million SPF-SIG, Kentucky was fortunate to have a well-developed system of support for local prevention efforts despite state budget shortfalls. This system included staff at the Division of Behavioral Health at the Cabinet for Health and Family Services (formerly the Division of Mental Health and Substance Abuse) dedicated to the support of substance abuse prevention activities throughout the state and maintenance of a prevention data system to capture information about the work of Regional Prevention Centers (RPC). Several other interrelated entities were also created to prevent substance abuse, including the Prevention Enhancement Site (PES) system in 1998 and the Kentucky Agency for Substance Abuse Policy (KY-ASAP) in 2000.

Upon receipt of the SPF-SIG in 2004, the prevention infrastructure was further bolstered to ensure the proper implementation of each SPF step, gain buy-in and support from state and community agencies, and provide additional data regarding special target populations, strategies, and policy measures. This occurred through the formation of the SIG Advisory Council, implementation of "home teams," development of the Master Trainer System, and creation of Kentucky's State Epidemiologic Outcomes Workgroup (SEOW) — originally called the Data Analysis Committee - that served as a subcommittee of Kentucky's preexisting Epidemiologic Workgroup. While the original workgroup primarily focused on treatment-related research, the SEOW analyzed and synthesized relevant datasets to determine statewide priorities and identify high-need regions to receive support throughout each of the five steps of the SPF process. 
In 2010, CSAP formally initiated the three-year SEOW Program to continue and enhance the work completed within the SPF-SIG while expanding the focus to include mental health promotion and the prevention of mental illness as it relates to substance abuse and its consequences. Upon receipt of the SEOW grant in September 2010, Kentucky continued institutionalizing data-driven capacity and surveillance through state and community profiles, a comprehensive dissemination plan, and systematic upgrades to the data warehouse originally developed during the SPF-SIG. Moreover, the expanded mental health focus led to the recruitment of professionals with mental health and epidemiologic backgrounds, as well as representatives from key state agencies spanning public health, drug enforcement, criminal and juvenile justice, education, and mental health.

Although the SEOW profiles consisted of mental and behavioral data spanning from major depression, serious psychological distress (SPD), suicide morbidity and mortality, and mental health care access, deriving real-time estimates proved to be a significant obstacle. ${ }^{10,11}$ Specifically, several regional estimates lagged by as much as six years, prompting the removal of these data from the revised state profile in $2012 .{ }^{11}$ Timely prevalence data of psychiatric morbidity among adults and adolescents in small areas therefore remain vital for mental health policy planning at the regional and local levels. Furthermore, effective regional policy planning also requires the measurement of psychiatric morbidity using clinically validated instruments as opposed to shortened proxy measures with no demonstrable psychometrics.

In response to these limitations, the SEOW convened in May 2012. As the KIP is administered to the vast majority of school districts throughout the state to produce 
regional and county-level estimates, a consensus was reached to add the $\mathrm{K} 6$ scale on the 2012 administration as a measure of serious emotional disturbance (SED) in the past 30 days. This choice was made since the $\mathrm{K} 6$ met core requirements for an effective screening instrument by being brief, self-administered, easy to score, and clinically relevant. ${ }^{12-14}$ Additionally, the K6 has been systematically implemented on numerous national health surveys, including the National Health Interview Survey (NHIS), the Behavioral Risk Factor Surveillance Survey (BRFSS), and the National Survey on Drug Use and Health (NSDUH).

The KIP is a particularly useful tool as schools are the leading providers of mental health services to children and adolescents in the US. ${ }^{15,16}$ Consequently, data regarding the school and community-level prevalence of SED are particularly valuable since local planning and resource allocation are partially driven by distribution of need (i.e., disorder prevalence and severity) in the public service sector. ${ }^{7-9,17}$ The inclusion of the K6 on the 2012 KIP therefore represents an opportunity to derive mental health data that may inform prevention and treatment efforts for Kentucky communities.

\section{The K6 Scale: Background and Characteristics}

Dimensional scales of non-specific SPD have evolved considerably since their original use in community epidemiologic surveys at the end of World War II. ${ }^{7}$ After PL 102-321 was published, the K6 scale was then developed as a brief measure of SMI to be included on the newly redesigned NHIS, with the goal of providing accurate aggregate estimates. During the early conceptualization of the K6, it was found that the vast majority of symptoms on scales of non-specific SPD had factor loadings on a first principal factor despite having a heterogeneous set of items spanning cognitive, 
behavioral, emotional, and pathophysiologic symptoms. ${ }^{18,19}$ Furthermore, individuals with a wide range of psychiatric morbidity typically have high scores on this core dimension of non-specific distress. ${ }^{7}$ The K6 was therefore developed as a very short scale using modern psychometric methods to select questions with the maximum precision at the clinical threshold of the scale. ${ }^{7}$ Based on past-year SMI estimates of $6-10 \%$ in the US, it was decided to seek maximum precision around the $90^{\text {th }}$ percentile of the general population distribution. ${ }^{7}$

Two independent clinical validation studies show that the K6 has very good concordance with blinded clinical diagnoses of SMI in general population samples of the US. $^{20,21}$ A small clinical reappraisal study classified respondents as cases if they met criteria for a 12-month DSM diagnosis of either an anxiety disorder, mood disorder, or non-affective psychosis on the Structured Clinical Interview for DSM Disorders (SCID) and had a global assessment of functioning (GAF) score in the range of $0-70 .{ }^{49}$ Receiver operator characteristic (ROC) curves were then estimated for standardized K6 scores that were generated using maximum-likelihood estimates computed with one- and twoparameter logistic regression models for binary scale items. ${ }^{49}$ This yielded very good discrimination, with area under the curve (AUC) of 0.879 for the $\mathrm{K} 6 .{ }^{49} \mathrm{~A}$ second calibration study found AUC of 0.86 and determined an optimal cut-point of $13+$ (i.e., coding items 0-4 and summing items to produce a scale ranging 0-24) that yielded sensitivity of 0.36 , specificity of 0.96 , and AUC of $0.92 .{ }^{50}$ More recently, results from the World Mental Health (WMH) Survey Initiative (combined $n=41,770$ from 14 countries) found high discrimination, with AUC ranging 0.76-0.89. 
For adolescents, two studies using data from the National Comorbidity Survey Replication Adolescent Supplement (NCS-A) suggest near-maximum precision of school-level SED prevalence estimates can be attained with the K6. ${ }^{17,22} \mathrm{Li}$ et al. focused on school-level estimates among 9,022 adolescents (ages 13-17 years) from a representative sample of 282 schools in the counties that participated in the NCS-A. ${ }^{11}$ A two-level multilevel model with bivariate outcomes was fit to these data, yielding a predicted 30-day SED prevalence of 5.7\%. ${ }^{11}$ Notably, the estimated correlation for concordance between the K6 and SED was very strong at the school level $(\rho=0.70)$ and the maximum reliability of small-area estimation could be approached with samples of $200-400$ students. $^{11}$

Green et al. found the K6 scale to be a fairly good predictor of adolescent SED (AUC $=0.74$ ) using an analytic subsample of 6,483 adolescents from the NCS-A. ${ }^{51}$ The strongest associations were with mood disorders (AUC from 0.74-0.77 for individual disorders and 0.77 for any mood disorder) and anxiety disorders (AUC from 0.69-0.82 for individual disorders and 0.73 for any anxiety disorder). ${ }^{22}$ The weakest associations were with behavior disorders (AUC from $0.58-0.75$ for individual disorders and 0.67 for any behavior disorder). Based on these results, a revised version of the $\mathrm{K} 6$ that included indicators of behavior disorders was tested and improved the AUC for any behavior disorder from 0.67 to $0.82 .{ }^{22}$

\section{Epidemiology of Child and Adolescent Psychiatric Morbidity}

It is now increasingly accepted that the field of psychiatric epidemiology has reached its maturity and efforts should shift to understanding how multiple risk factors

interact over time in producing multiple, interrelated outcomes. ${ }^{23,24}$ This suggests the 
evolution of psychiatric epidemiology partially hinges upon the continued incorporation of principles from developmental psychopathology to further understand how the trajectories of behavioral phenotypes, environments, and individual development interact to produce psychiatric morbidity. ${ }^{1,25}$

Nonetheless, child and adolescent psychiatric epidemiology remains particularly salient as both retrospective and prospective research consistently shows that the majority of adult psychiatric morbidity emerges in childhood and adolescence. ${ }^{1,25-27}$ Recent studies suggest that more than one-fourth of all US children and adolescents meet criteria for a lifetime mental disorder defined in the Diagnostic and Statistical Manual of Mental Disorders, Fourth Edition (DSM-IV) ${ }^{25,28}$ About one out of every ten adolescents is estimated to meet SAMHSA's 12-month criteria for SED defined as a diagnosable mental, behavioral, or emotional disorder that meets DSM criteria and results in functional impairment that substantially interferes with or limits the child's role or functioning in family, school, or community activities. ${ }^{25,29}$ Moreover, numerous studies have applied DSM-IV criteria to estimate the incidence and prevalence of depressive, anxiety, behavior, and substance use disorders, the four disorder classes most common among adolescents (see Appendices 1-11 for disorder criteria). ${ }^{30,31}$

For major depressive disorder (MDD), community studies show a median prevalence of $4.0 \%$ and range $0.2-17 \% .{ }^{1}$ More recently, data from the NCS-A found a 12-month and 30-day prevalence of $8.2 \%$ and 2.6\%, respectively, for MDD and dysthymia combined. ${ }^{30}$ NCS-A data also indicate $30 \%$ of SED cases are due to MDD and dysthymia. ${ }^{32}$ Prospective studies suggest an average age of onset between 11 and 14 years, with evidence that incident MDD accelerates from $1 \%$ to $2 \%$ at age 13 and from 
$3 \%$ to $7 \%$ at age $15 .{ }^{1}$ While no gender differences have been found during preadolescence, rates of depression tend to be higher among females than males during adolescence, with differences persisting into middle adulthood. ${ }^{1}$

Anxiety disorders are the most common class of disorders among adolescents. Studies show a median prevalence of $8 \%$ with a wide range from $2 \%$ to $24 \% .{ }^{1}$ Similarly, the NCS-A found a 12 -month and 30-day prevalence of $24.9 \%$ and $14.9 \%$, respectively, for any anxiety disorder. ${ }^{30}$ More specifically, specific phobia and social phobia emerged as the most common anxiety disorders in the NCS-A, although other studies have found generalized anxiety disorder (GAD) to be more common. ${ }^{30,33-35}$ Anxiety disorders, however, only accounted for roughly $11 \%$ of SED cases in the NCS-A. ${ }^{32}$ While females tend to have a steep increase in anxiety by age five and a continuously increasing rate throughout adolescence, males tend to have a gradual increase that levels off in late adolescence. ${ }^{1}$ Despite these more rapid increases for females, no gender differences are evident for the mean age at onset and duration. ${ }^{1}$

Behavior disorders are also common among adolescents, with the NCS-A finding a 12 -month and 30-day prevalence of $16.3 \%$ and $7.6 \%$, respectively, for any behavior disorder. ${ }^{30}$ Like anxiety disorders, the incidence and prevalence of behavior disorders vary by disorder type. For example, the 12-month prevalence of attention deficit hyperactivity disorder (ADHD) ranges $2-8.7 \%$ with a median prevalence of $4 \% .{ }^{34-36}$ In the NCS-A, the 12-month prevalence of ADHD (6.5\%) fell into this range. ${ }^{30}$ Similarly, 12-month prevalence of disruptive behavior disorders (i.e., conduct disorder [CD] and oppositional-defiant disorder [ODD]) ranges 5-14\% with a median prevalence of $6 \%$, consistent with the NCS-A cumulative prevalence of approximately $13.7 \% .{ }^{1,30}$ Clinical 
and community studies also show higher rates of behavior disorders among males, although data are mixed for ODD. ${ }^{37-39}$ Notably, behavior disorders accounted for roughly $55 \%$ of SED cases in the NCS-A sample, the highest among all disorder classes. ${ }^{32}$

Substance use disorders also witness a marked increase in prevalence from early to late adolescence. ${ }^{26}$ Estimates from major health surveys indicate that by age 17, most adolescents (59-71\%) have consumed alcohol, 31-44\% have tried marijuana, and 4-6\% have tried cocaine ${ }^{40}$ While there is a dearth of data regarding the full trajectory of substance use disorders in adolescence, the NCS-A has shown large increases in the cumulative incidence of substance use disorders between ages 13 and 18 and an overall lifetime prevalence that approaches rates found in adult populations. ${ }^{41-44}$ Specifically, the lifetime prevalence of alcohol abuse with or without dependence ranged from 1.3\% among 13-14 year olds to $15.1 \%$ among 17-18 year olds, with a median age of onset of 13 years for first alcohol use and 14 years for regular use or abuse (with or without dependence). ${ }^{40}$ For lifetime illicit drug abuse, rates were slightly higher than alcohol and ranged from $3.4 \%$ among $13-14$ year olds to $16.4 \%$ among $17-18$ year olds. ${ }^{40}$ The median ages of onset were comparable to alcohol with 14 years for the first illicit drug use, 14 years for drug abuse with dependence, and 15 years for drug abuse without dependence. ${ }^{40}$

Although a multitude of national surveys use structured diagnostic interviews to derive estimates for DSM disorders among adolescents, similar state and regional estimates in Kentucky are limited. The NSDUH is the only survey to date that uses diagnostic interviews to derive clinically relevant estimates for Kentucky adolescents. Specifically, the NSDUH measures past-year major depressive episode (MDE) and substance use disorders using questions adapted from the World Health Organization 
Composite International Diagnostic Interview (WHO-CIDI) that is also used in the NCS-

A. Based on combined 2010-2011 data, the estimated prevalence of MDE among 12-17 year olds in Kentucky was $8.9 \%$, marginally higher than the national estimate of $8.2 \% .{ }^{45}$ Similarly, the past-year prevalence of alcohol abuse with or without dependence was $3.6 \%$ for Kentucky and $4.2 \%$ for the US; and the past-year prevalence of illicit drug abuse with or without dependence was $4.8 \%$ for Kentucky and $4.7 \%$ for the US. ${ }^{45}$ The NSDUH also produces small area estimates of the prevalence of substance use and mental disorders in substate regions (Figure 2) through a hierarchical Bayes estimation method that combines data with a national model. ${ }^{46}$

Figure 2. Substate regions in Kentucky. ${ }^{45,46}$

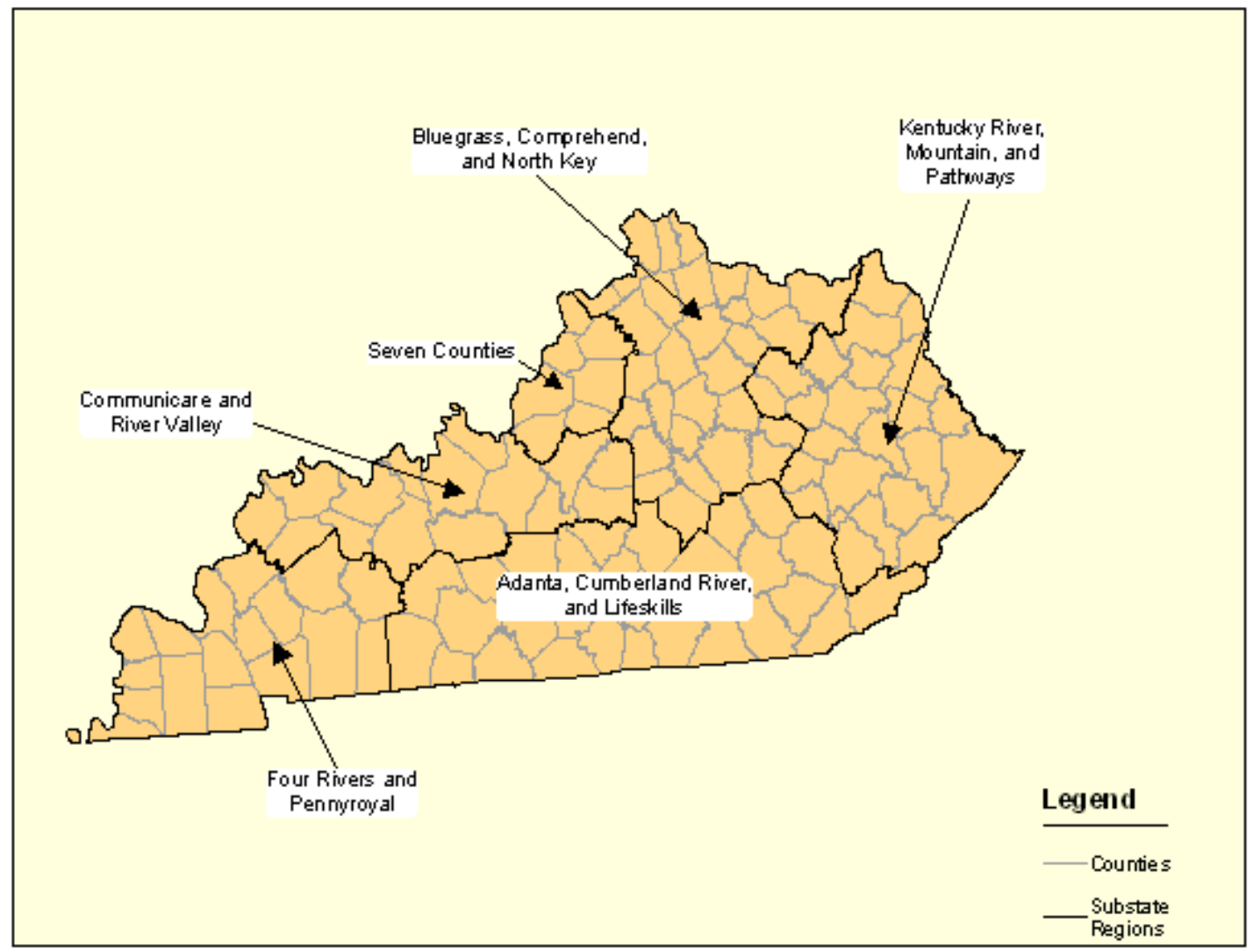

These synthetic estimation methods, however, frequently lead to imprecise estimates. ${ }^{17,46,47}$ Moreover, diagnostic interviews can be time-consuming, burdensome, 
and costly, especially within school settings. Psychiatric morbidity among Kentucky adolescents therefore tends to be estimated with self-report questions, and in the case of substance abuse, estimates are drug-specific. Despite these limitations, the SEOW continues to integrate a variety of data sources for the surveillance of child and adolescent psychiatric morbidity, such as the Youth Risk Behavior Survey (YRBS), the National Study on Children's Health (NCSH), the Treatment Episode Data Set Admissions (TEDS-A), and the KIP. ${ }^{10,11}$

According to the $2007 \mathrm{NCSH}$, Kentucky children 2-17 years old had higher lifetime rates than the US for ADHD (11\% vs. $8.4 \%$ ), depression (4.3\% vs. 3.7\%), anxiety (5.6\% vs. 4.5\%), and conduct disorders (4.9\% vs. 4.4\%). ${ }^{10,11}$ Among Kentucky high school students in 2011, the prevalence of past-year depressive symptoms was $27 \%$, slightly lower than the US rate of $28.5 \%{ }^{48}$ Cigarette smoking, binge alcohol use, and prescription drug abuse are also particularly endemic to Kentucky and were recently identified as priority areas for targeted prevention by the Division of Behavioral Health through SEOW recommendations. ${ }^{10,11}$

Kentucky's adolescent smoking rates consistently exceed national levels. According to the 2009 YRBS, 26.1\% of Kentucky high school students were past-month cigarette users compared to $18.2 \%$ nationally. ${ }^{49}$ Among Kentucky residents who report having a family member who smokes cigarettes, pipes, or cigars, $45 \%$ indicate a family member smokes inside the house with a child, vastly higher than $29 \%$ nationally. ${ }^{10,11}$ Although the past-month alcohol use among $10^{\text {th }}$ graders in Kentucky $(26.1 \%)$ was slightly lower than the national average $(28.9 \%)$ in $2010,21 \%$ reported being drunk in the past month in Kentucky compared to $14.7 \%$ nationally. ${ }^{10,11}$ Nearly $8 \%$ of $12-17$ year 
olds in Kentucky report nonmedical opioid use compared to $6.6 \%$ nationally. ${ }^{10,11}$ Between 2000 and 2010, the incidence of opioid and tranquilizer treatment admissions increased for both the US and Kentucky among 12-24 year olds, with significant increases for Kentucky: for opioids admissions, the incidence increased from $0.9 \%$ to $4.3 \%$ in the US and $2.5 \%$ to $16.9 \%$ for Kentucky; and for tranquilizer admissions, the US increased from $0.7 \%$ to $1.6 \%$ and $2.9 \%$ to $7.1 \%$ for Kentucky. ${ }^{10,11}$

The prevalence of DSM disorders in national and state samples has nonetheless raised concerns regarding the clinical significance of DSM criteria. ${ }^{50}$ Research has shown that estimates of child and adolescent psychiatric morbidity significantly decrease when role impairments are included in making diagnoses. ${ }^{5,51}$ Previous studies estimate that 4$14 \%$ of US adolescents meet 12 -month criteria for SED ${ }^{1}$ Most recently, the 12-month prevalence of SED was $8 \%$ among NCS-A respondents with complete adolescent-parent data. $^{32}$

Given a 12 -month prevalence of $42.6 \%$ for any disorder, it was estimated that $18.8 \%$ of adolescents with a disorder met criteria for SED. ${ }^{32}$ In particular, $54.5 \%$ of SED cases were due to behavior disorders, $31.4 \%$ to any mood disorder, $10.9 \%$ to any anxiety disorder, and $1.9 \%$ to any substance use disorder. ${ }^{32}$ The strongest predictor of SED involved high comorbidity as adolescents with $\geq 3$ disorders made up $29 \%$ of those with DSM-IV disorders, but comprised $63.5 \%$ of SEDs. ${ }^{32}$ This suggests the grouping of symptom clusters into distinct disorders in the DSM may not be the most parsimonious method. ${ }^{28,39,52}$ Furthermore, the lack of significant association between social and demographic factors and SED when type and number of disorders are controlled for in 
estimates suggests SED is more of a function of multivariate disorder profiles, with high comorbidity playing a critical role. ${ }^{32}$

\section{Psychiatric Comorbidity and Heterogeneity}

Considering the comorbidity and widespread heterogeneity found in the NCS-A, ${ }^{32}$ there have been concerted efforts to identify distinct subtypes of psychiatric morbidity, namely major depression and anxiety disorders, based upon severity and symptom clusters. ${ }^{53-74}$ Similarly, the significant overlap between depressive and anxiety disorders challenges the assumption that their classification as distinct disorders is both theoretically and empirically meaningful. ${ }^{72-74}$

Data-driven techniques that cluster individuals on the basis of reported symptom patterns have therefore been increasingly applied to arrive at more empirically based classifications. In contrast to variable-centered approaches, such as factor analysis that classify variables into a restricted number of dimensional constructs based upon their covariation, person-centered approaches like latent class analysis (LCA) focus on the classification of individuals into mutually exclusive categories based on similar symptom patterns.$^{57}$ Specifically, LCA assigns individuals to probabilistic subclasses based upon shared features that discriminate members of one class from another. ${ }^{57}$ Because LCA identifies subclasses that share common characteristics, this method provides different information than variable-level techniques and may be more relevant to mental health treatment, prevention, practice, and policy. ${ }^{69,70}$

While the preponderance of studies using LCA to examine subtypes of depression and anxiety have been conducted with adult samples, several studies have explored heterogeneity among adolescents from clinical and community samples. Using parent 
ratings on the Child Behavior Checklist Anxious/Depressed Scale (CBCL-A/D), Wadsworth et al. identified three classes consisting of mixed anxiety and depressive symptom types that all varied by symptom severity in a sample of non-referred and clinically referred ( $\mathrm{n}=1,987 ; 4-18$ years) children and adolescents. ${ }^{64}$ In another study, Ferdinand et al. used the Youth Self Report (YSR) and Revised Child Anxiety and Depression Scale (RCADS) in a community sample of 2,210 10-12 year olds. ${ }^{65}$ Five classes were identified that differed by severity (never versus sometimes, often, or always), but no class demonstrated a perfect correspondence to any disorder. ${ }^{65}$ Similarly, Williams et al. identified three classes that differed primarily by symptom severity (i.e., number of externalizing symptoms) in a sample of 224 6-16 year olds referred for an anxiety disorder. ${ }^{66}$ In a school-based sample of sixth graders ( $\left.\mathrm{n}=2,187\right)$, Mezulis et al. identified six classes that differed primarily by total number of depressive and externalizing symptoms endorsed, not type of symptoms endorsed. ${ }^{67}$

Conversely, a 2005 study used the YSR with clinically referred adolescents $(\mathrm{n}=2,032 ; 11-18$ years $)$ to identify seven classes that differed primarily by symptom type: three anxiety problem classes and four affective problem classes. ${ }^{68}$ Similarly, in a sample of 2,539 13-18 year olds from the NCS-A, Burstein et al. also identified seven classes of adolescents with lifetime anxiety disorders that were characterized by disorder type rather than the degree or number of disorders. ${ }^{69}$ In a 2001 study of 2,904 female twins aged 1323 years, nine classes were found to differ by type of externalizing and internalizing symptom rather than symptom severity. ${ }^{71}$

Lamers et al., however, found three subtypes of 12-month major depressive disorder among 912 adolescents from the NCS-A that differed by both symptom type and 
severity. ${ }^{70}$ Compared with the moderate subtype, the severe subtype was characterized by a greater number of depressive symptoms, number of depressive episodes, symptom severity, and role impairments. ${ }^{70}$ Furthermore, the two severe subtypes (atypical and typical) possessed differential symptom profiles. In particular, the typical subtype was characterized by more loss of appetite and weight loss, psychomotor change and feelings of guilt, while the atypical tended to be defined by increased appetite and weight gain along with increased rates of binge eating disorder and higher body mass index (BMI). ${ }^{70}$

Collectively, the findings from these studies suggest both symptom type and severity are sources of heterogeneity in adolescent depression and anxiety. Compared to adults, behavioral and somatic symptoms may be more common, and psychomotor symptoms less. ${ }^{70}$ Considering the somatic nature of classifying disorders subtypes has implications for understanding pathophysiologic differences and how these differences may influence prevention and treatment. ${ }^{70}$ The application of the $\mathrm{K} 6$ therefore becomes particularly relevant to explore psychiatric comorbidity as it possesses a heterogeneous set of items spanning cognitive, behavioral, emotional, and pathophysiologic symptoms that comprise non-specific SPD. ${ }^{7,20,21}$ As individuals with a wide range of psychiatric morbidity typically have higher scores on this core dimension, the evaluation of K6 scores from the 2012 KIP using LCA represents an opportunity to elucidate on the heterogeneity of SED and further inform prevention efforts in Kentucky.

\section{Present Study}

Based upon the demonstrated utility of the K6 in adult and adolescent populations throughout the world, this dissertation possesses three aims to examine the performance of the K6 on the 2012 KIP ( $n=108,736)$. First, principal axis and confirmatory factor 
analysis are performed to determine the unidimensional structure of the $\mathrm{K} 6$ in a schoolbased sample of Kentucky students. Second, the unweighted scoring algorithm (i.e., scores $13+$ ) is used to screen Kentucky students for SED, estimate the state prevalence of SED, and define epidemiologic correlates. Lastly, LCA is conducted to empirically derive subclasses of students who screen positive for SED. 


\section{CHAPTER II}

\section{METHODS}

\section{KIP Survey: Background, Field Procedures, and Sample}

The KIP Survey has been administered to Kentucky students for more than a decade through the Substance Abuse Prevention Program in the Cabinet for Health and Family Services, through agreements with individual school districts across the state. ${ }^{75}$ The intent of the survey is to anonymously assess student use of alcohol, tobacco, and other drugs (ATOD) as well as a number of factors related to potential substance abuse (e.g., peer influences, risk perceptions, and school safety). ${ }^{75}$ In 2006 , three questions on gambling were added to the survey; and in 2012, the K6 was added. School district and individual student participation have always been on a voluntary basis.

Originally, the KIP Survey was used as part of a federal initiative that funded state incentive grants for substance abuse prevention throughout the nation. In Kentucky, these programs were called the Kentucky Incentives for Prevention program, hence the name KIP. ${ }^{75}$ The core items on the KIP were originally chosen by CSAP based upon extensive research on risk and protective factors associated with child and adolescent substance abuse. ${ }^{75}$ This federal model enables comparisons to other states and to the nation, while facilitating regional comparisons within the state.

The survey is now administered biennially in the fall of even-numbered years (i.e., 2004, 2006, 2008, etc.) to $6^{\text {th }}, 8^{\text {th }}, 10^{\text {th }}$, and $12^{\text {th }}$ graders attending schools throughout Kentucky. There is no cost to the individual districts as all costs are paid by the 
Substance Abuse Prevention Program. Extensive efforts are made to ensure student anonymity and minimize coercion to participate. The survey uses a passive consent model: parents who do not wish for their child to participate are given opportunities through general and specific notifications that they may refuse on behalf of their child.

Effective with the 2008 administration, both a paper-pencil and web-based version of the KIP survey were made available to school districts. Classroom administration of the paper-pencil survey (including distribution, giving instructions, completing the survey, and collecting the survey) takes approximately 45 minutes. ${ }^{75}$ The surveys are administered to classroom groups, sent to a service agency for electronic scanning, and then analyzed by REACH Evaluation, who provides each school district with a comprehensive report of their findings. Administration of the survey typically occurs within an approximate 5-week window in the fall and results are disseminated to school districts in three to four months proceeding administration.

In 2012, the KIP survey was administered to 154 Kentucky school districts out of a total of 173 school districts, yielding an $89 \%$ participation rate. Among the 154 participating school districts, a total of 122,718 students completed the survey and of these students, approximately $89 \%$ fully completed the K6 scale $(n=108,736)$. Table 1 shows the demographic distribution of the KIP survey respondents compared to enrollment data from the Kentucky Department of Education. Although the survey does not include data from school districts in Jefferson County, the grade and gender distributions of the KIP are highly comparable. The racial and ethnic composition of the KIP, however, tends to underrepresent Blacks, but this difference becomes marginal when Jefferson County schools are removed from enrollment data. 
Table 1. Social and Demographic Factors of Kentucky Students

\begin{tabular}{|c|c|c|c|c|c|c|}
\hline \multirow{4}{*}{$\begin{array}{l}\text { Characteristics } \\
\text { Grade } \\
\quad 6\end{array}$} & \multicolumn{6}{|c|}{ Kentucky Students 2012, n (\%) } \\
\hline & \multicolumn{2}{|c|}{$\begin{array}{c}\text { KIP 2012 } \\
(\mathrm{N}=122,718)\end{array}$} & \multicolumn{2}{|c|}{$\begin{array}{l}\text { KY Enrollment } \\
(\mathrm{N}=193,153)^{\mathrm{a}}\end{array}$} & \multicolumn{2}{|c|}{$\begin{array}{c}\text { KY Enrollment } \\
(\mathrm{N}=164,926)^{\mathrm{b}}\end{array}$} \\
\hline & & & & & & \\
\hline & 34,262 & $(27.9)$ & 51,080 & $(26.5)$ & 43,632 & $(26.5)$ \\
\hline 8 & 33,523 & $(27.3)$ & 50,094 & (25.9) & 42,782 & (25.9) \\
\hline 10 & 29,988 & (24.4) & 48,625 & $(25.2)$ & 41,534 & $(25.2)$ \\
\hline 12 & 24,945 & (20.3) & 43,354 & $(22.5)$ & 36,978 & $(22.4)$ \\
\hline Missing & \multicolumn{2}{|c|}{-} & \multicolumn{2}{|c|}{ - } & \multicolumn{2}{|c|}{ - } \\
\hline \multicolumn{7}{|l|}{ Gender } \\
\hline Male & 59,642 & $(51.8)$ & 99,011 & $(51.3)$ & 84,789 & $(51.4)$ \\
\hline Female & 55,408 & $(48.2)$ & 94,142 & $(48.7)$ & 80,137 & $(48.6)$ \\
\hline Missing & 7,668 & - & & & & - \\
\hline \multicolumn{7}{|l|}{ Race/Ethnicity } \\
\hline White & 97,713 & $(84.0)$ & 159,872 & $(82.8)$ & 144,779 & $(87.8)$ \\
\hline Black & 7,609 & $(6.5)$ & 21,028 & $(10.9)$ & 10,721 & $(6.5)$ \\
\hline Hispanic & 3,626 & (3.1) & 6,197 & $(3.2)$ & 4,707 & $(2.9)$ \\
\hline AA/PI & 1,291 & (1.1) & 2,655 & (1.4) & 1,760 & $(1.1)$ \\
\hline Other & 6,150 & $(5.3)$ & 3,401 & $(1.8)$ & 2,959 & $(1.8)$ \\
\hline Missing & 6,329 & - & & & & - \\
\hline
\end{tabular}

Abbreviation: KIP, Kentucky Incentives for Prevention; KY, Kentucky; AA/PI, Asian-American and Pacific Islander.

${ }^{\mathrm{a}}$ Total enrollment for grades $6,8,10$, and 12 with Jefferson County schools.

${ }^{\mathrm{b}}$ Total enrollment for grades 6, 8, 10, and 12 without Jefferson County schools.

\section{Social and Demographic Factors}

A variety of self-reported social and demographic factors were included in analyses: sex (classified as Male or Female), grade $(6,8,10$, and 12), and race/ethnicity (classified as White, Black, Hispanic, Asian American/Pacific Islander [AA/PI], Native American [NA], and Other). Family structure included living with both parents, mother only, father only, mother and stepfather, father and stepmother, or other (classified as having 1 or 2 biological parents, or other). Data regarding the percentage of youth in poverty and population density were inputted from 2012 US Census estimates for each Kentucky county.

\section{Substance Abuse and Antisocial Behavior}

The KIP asks a series of questions about the frequency of tobacco, alcohol, marijuana, and illicit drug abuse in the lifetime, past year, and past month. Item 
responses range from $0,1-2,3-5,6-9,10-19,20-39$, and 40+ occasions. Past-month substance abuse variables were dichotomized as 0 or $1+$ occasions for cigarettes, binge drinking, and marijuana abuse. For illicit drugs, past-year abuse of cocaine, ecstasy, methamphetamines, speed/uppers, and inhalants on 1+ occasions were included. For prescription drugs, past-year abuse of opioids and tranquilizers on $1+$ occasions were included. Four items ask students about the frequency of taking a handgun to school, selling illegal drugs, attacking someone (i.e., fighting), and being drunk or high at school using the aforementioned item responses and groupings for the past year. Past-year antisocial behaviors were dichotomized as 0 or $1+$ occasions.

\section{Role Impairments}

Several questions address school, legal, and substance-related role impairments. Students are asked if they have been suspended from school and arrested in the past year. Students are also asked if their drinking or drug abuse has caused them in the past year to get stopped by the police for drunk driving or disorderly conduct, get in trouble at school, get into verbal or physical fights with other kids, get into fights with their parents, and to be involved in a car accident.

\section{Peer Victimization}

Four yes or no questions address experiences of peer victimization at school in the past year. Students are asked if someone took money or things directly from them by using force, weapons, or threats. Students are also asked if someone verbally or physically threatened or attacked them at school. Lastly, students are asked if someone made unwanted sexual advances or attempted to sexually assault them at school.

\section{K6 Scale}


The version of the K6 included on the 2012 KIP consists of six questions that ask respondents how frequently they felt 1) nervous, 2) hopeless, 3) restless or fidgety, 4) so depressed that nothing cheer you up, 5) that everything was an effort, and 6) worthless in the past 30 days. $^{20}$ The following item responses were used: never, a little of the time, some of the time, most of the time, and all of the time. These responses were coded 0-4 generating an unweighted summary scale with a range of $0-24 .{ }^{21}$ Previous research suggests that dichotomous scoring of $13+$ versus 0-12 discriminates between respondents with and without SED with good accuracy. ${ }^{21}$ This scoring algorithm was utilized to screen Kentucky students for SED.

\section{Aim 1: Confirm the Unidimensional Structure of the K6}

Six-by-six matrices of polychoric correlations among the K6 items were generated using the polychoric module in Stata $12.1 .^{76,77}$ Principal axis factor analysis was then carried out using the generated polychoric correlation matrix that allows for nonlinear monotonic relationships between pairs of variables. ${ }^{7}$ Unidimensionality was supported if this factor analysis revealed a large first unrotated eigenvalue and a second unrotated eigenvalue less than $1.0 .^{7}$

Confirmatory factor analysis (CFA) was then performed using the sem procedure in Stata 12.1 using maximum likelihood estimation. ${ }^{76}$ Global model fit was determined using the $\chi^{2}$ test, the comparative fit index (CFI), the Tucker-Lewis Index (TLI), and the root mean square error of approximation (RMSEA). ${ }^{76}$ The magnitudes of these indices were determined using established criteria. ${ }^{78}$ For $\chi^{2}$, values closer to zero are optimal; for CFI and TLI, $\geq 0.90$ was considered adequate and $>0.95$ very good; and for RMSEA, $\leq 0.08$ was considered adequate and $\leq 0.05$ very good. ${ }^{78}$ An identical CFA was also 
performed in Mplus Version 7 using the robust weighted least squares estimator (WLSMV) that has been shown to be optimal for ordinal responses like those on the K6. ${ }^{78,79}$

\section{Aim 2: Estimate the State Prevalence of SED and Explore Epidemiologic Correlates}

Using the unweighted scoring algorithm, the 30-day prevalence of SED was calculated for Kentucky. The distribution of SED was examined for each social and demographic characteristic using cross-tabulations. Unadjusted relative risks (RR) and $95 \%$ confidence intervals $(95 \% \mathrm{CI})$ were estimated by fitting logistic regression models to determine statistically meaningful social and demographic predictors of SED. Bivariate associations were used as a previous study found that bivariate associations did not significantly differ from multivariate associations. ${ }^{32}$ Cross-tabulations were also used to explore the prevalence of substance abuse, antisocial behaviors, role impairments, and peer victimization among students with and without SED.

\section{Aim 3: Empirically Derive Subclasses of Students Who Screen Positive for SED}

Using Mplus Version 7, each K6 item was entered into a latent class model and proceeded monotonically until the most parsimonious model was found. ${ }^{80}$ Model fit was based upon three information criteria: adjusted Bayesian information criterion (aBIC), Lo-Mendell-Rubin likelihood ratio test (LMR-LRT), and model entropy. ${ }^{80}$ For aBIC, lower values indicate a better model fit. ${ }^{80}$ The LMR-LRT yields a $p$-value, with values less than 0.05 indicating that the estimated model provides a better fit than the previous model with one less class. ${ }^{80}$ Entropy values closer to 1 indicate more accuracy and precision in classification. ${ }^{80}$ Of note, the aBIC was chosen over the Akaike information criterion (AIC) and Bayesian information criterion (BIC) as this criterion has been shown 
to be one of the most robust indicators of model fit when determining the optimal number of classes. $^{80,81}$

The distribution of social and demographic factors, role impairments, antisocial behaviors, substance abuse, and peer victimization were analyzed for each subclass using cross-tabulations. These variables were then entered into a multinomial logistic regression model using mlogit in Stata 12.1 to determine significant predictors of class membership with students receiving a negative SED screen serving as a base outcome. ${ }^{76}$ This produced RR's and 95\% CI's for each predictor. All statistical tests were two-sided with alpha set at the 0.05 level. 


\section{CHAPTER III}

\section{RESULTS}

\section{Distribution and Factor Structure of the K6}

The distribution of K6 scores (Figure 3) in the 2012 KIP is fairly comparable to those found in the NCS-A, ${ }^{22}$ with a J-shaped curve that includes approximately $50 \%$ of respondents with scores of $0(24.1 \%), 1(10.3 \%), 2(8.6 \%)$, and $3(7.1 \%)$. The K6 items all have high polychoric correlations that range $0.63-0.87$ (Table 2). Principal axis factor analysis yields a strong first factor (eigenvalue $=4.6$ ) and no second factor (eigenvalue $=$ $0.5)$.

Figure 3. Distribution of K6 scores.

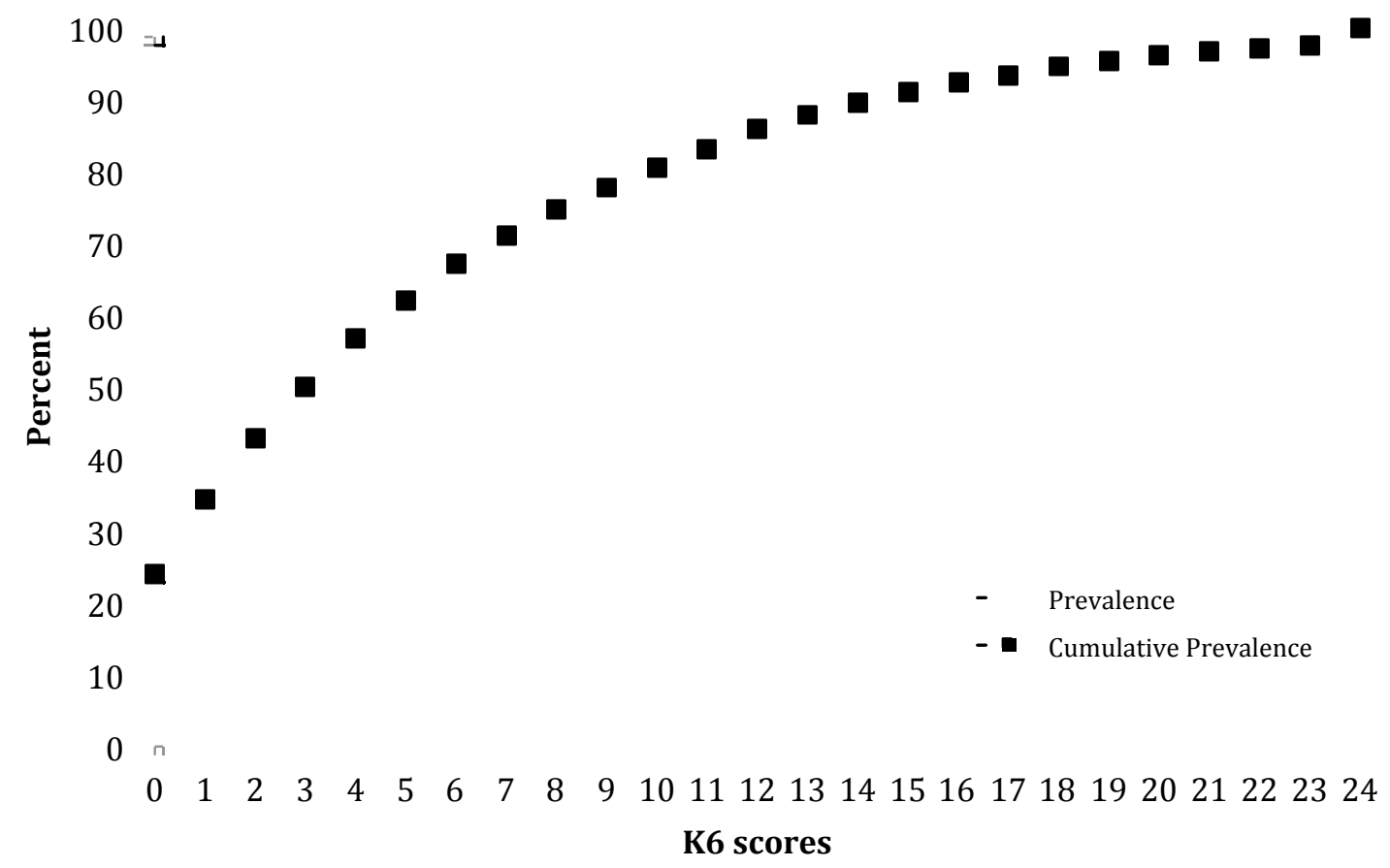


Table 2. Principal Axis Factor Analysis of the Polychoric Correlation Matrix of K6 Items

\begin{tabular}{|lllllll|}
\hline K6 Items & $\mathbf{1}$ & $\mathbf{2}$ & $\mathbf{3}$ & $\mathbf{4}$ & $\mathbf{5}$ & $\mathbf{6}$ \\
\hline Nervous & 1 & & & & & \\
Hopeless & 0.72 & 1 & & & & \\
Restless/Fidgety & 0.67 & 0.72 & 1 & & & \\
So depressed... & 0.65 & 0.84 & 0.68 & 1 & 1 & \\
Everything an effort & 0.63 & 0.70 & 0.67 & 0.70 & 1 \\
Worthless & 0.65 & 0.87 & 0.68 & 0.87 & 0.70 & $1.01(1.31)$ \\
Mean (SD) & $1.22(1.19)$ & $0.79(1.20)$ & $1.06(1.31)$ & $0.75(1.19)$ & $0.74(1.25)$ \\
Factor loading & 0.82 & 0.93 & 0.84 & 0.91 & 0.84 & 0.91 \\
\hline
\end{tabular}

In the CFA, CFI is very good at 0.962 , TLI is adequate at 0.937 , and RMSEA is inadequate at 0.125 (Table 3). When the residuals are correlated using post-hoc modification indices (see Appendix 12 for final model specification), CFI improves to 0.999, TLI to 0.989 , and RMSEA to 0.052 . The $\chi_{(\mathrm{df})}^{2}$ from the unspecified model also decreases from $15,221.92_{(9)}$ to $579.33_{(2)}$.

Table 3. Global Model Fit Statistics from Confirmatory Factor Analysis of K6 Items

\begin{tabular}{|c|c|c|c|c|}
\hline Model & $\chi_{(\mathrm{df})}^{2}$ & CFI & TLI & RMSEA \\
\hline 1. 1-Factor - No Correlated Residuals & $15,221.92_{(9)}$ & 0.962 & 0.937 & 0.125 \\
\hline 2. 1-Factor-Correlated Residuals & $579.33_{(2)}$ & 0.999 & 0.989 & 0.052 \\
\hline 3. 1-Factor - Correlated Residuals & $571.64_{(2)}^{(2)}$ & 0.999 & 0.997 & 0.049 \\
\hline
\end{tabular}

Abbreviation: $\chi_{(\mathbf{d f})}^{2}$, chi-square (degrees of freedom); CFI, comparative fit index; TLI, Tucker-Lewis Index; RMSEA, root mean square of error of approximation

${ }^{a}$ An identical confirmatory factor model with correlated residuals was fit using the robust weighted least squares estimator (WLSMV) that has been shown to be optimal for ordinal responses like those on the K6. This produced results that were virtually identical to the model estimated using the maximum likelihood method.

\section{Social and Demographic Correlates of SED}

The overall 30-day prevalence of SED is $13.9 \%$. Grade, gender, race/ethnicity, and family structure are significant social and demographic predictors (Table 4). Compared to $6^{\text {th }}$ graders, $10^{\text {th }}$ graders have the highest relative risk of SED (RR=1.98, 95\%CI 1.88-2.08). Females have a significantly higher risk of SED than males $(\mathrm{RR}=1.87,95 \% \mathrm{CI} 1.80-1.94)$. Students with one biological parent $(\mathrm{RR}=1.62,95 \% \mathrm{CI}$ 1.57-1.69) and Other living situations ( $R R=2.06,95 \% \mathrm{CI} 1.95-2.17)$ have significantly 
higher risk of SED than those with two biological parents. Hispanic students $(R R=1.12$, 95\% CI 1.01-1.23) and Other races ( $\mathrm{RR}=1.45,95 \% \mathrm{CI} 1.49-1.74)$ have higher risk of SED than White students.

Table 4. Social and Demographic Correlates of Serious Emotional Disturbance

\begin{tabular}{|c|c|c|}
\hline \multirow[b]{2}{*}{ Characteristics } & \multicolumn{2}{|c|}{ Prevalence of SED } \\
\hline & $\%(95 \% \mathrm{CI})$ & RR $(95 \% C I)$ \\
\hline Overall & $13.9(13.7-14.1)$ & \\
\hline \multicolumn{3}{|l|}{ Grade } \\
\hline 6 & $9.6(9.2-9.9)$ & 1.00 \\
\hline 8 & $13.5(13.1-13.9)$ & $1.48(1.40-1.56)$ \\
\hline 10 & $17.3(16.9-17.8)$ & $1.98(1.88-2.08)$ \\
\hline 12 & $16.1(15.6-16.6)$ & $1.81(1.72-1.91)$ \\
\hline \multicolumn{3}{|l|}{ Gender } \\
\hline Male & $10.2(9.9-10.5)$ & 1.00 \\
\hline Female & $17.5(17.1-17.8)$ & $1.87(1.80-1.94)$ \\
\hline \multicolumn{3}{|l|}{ Biological Parents } \\
\hline 1 & $16.6(16.2-16.9)$ & $1.62(1.57-1.69)$ \\
\hline 2 & $10.9(10.6-11.1)$ & 1.00 \\
\hline Other & $20.0(19.3-20.8)$ & $2.06(1.95-2.17)$ \\
\hline \multicolumn{3}{|l|}{ Race/Ethnicity } \\
\hline White & $13.7(13.4-13.9)$ & 1.00 \\
\hline Black & $13.4(12.6-14.2)$ & $0.98(0.91-1.05)$ \\
\hline Hispanic & $15.0(13.8-16.3)$ & $1.12(1.01-1.23)$ \\
\hline AA/PI & $14.8(12.9-17.0)$ & $1.10(0.93-1.29)$ \\
\hline Other & $18.6(17.6-19.7)$ & $1.45(1.35-1.55)$ \\
\hline \multicolumn{3}{|l|}{ Youth Poverty (\%) } \\
\hline $10.7-20.9$ & $13.7(13.2-14.1)$ & 1.00 \\
\hline $21.1-24.6$ & $14.1(13.7-14.6)$ & $1.04(0.99-1.09)$ \\
\hline $25.1-30.7$ & $14.1(13.7-14.5)$ & $1.04(0.99-1.09)$ \\
\hline $30.9-52.8$ & $13.9(13.5-14.3)$ & $1.02(0.97-1.07)$ \\
\hline \multicolumn{3}{|l|}{ Population Density } \\
\hline $2,188-19,978$ & $14.0(13.6-14.5)$ & 1.00 \\
\hline $20,071-37,544$ & $14.0(13.6-14.4)$ & $1.00(0.95-1.05)$ \\
\hline $37,655-75,427$ & $13.9(13.5-14.3)$ & $0.99(0.94-1.04)$ \\
\hline $75,896-305,489$ & $13.8(13.4-14.2)$ & $0.98(0.94-1.03)$ \\
\hline
\end{tabular}

Abbreviation: SED, serious emotional disturbance; RR, relative risk; $95 \% \mathrm{CI}, 95 \%$ confidence interval; AA/PI, Asian-American and Pacific Islander.

\section{Substance Abuse, Antisocial Behavior, and Role Impairments}

The prevalence rates for cigarette smoking (23.4\%), binge drinking $(15.3 \%)$, and marijuana abuse (15.6\%) for students with SED are approximately twice as high as students without SED (Table 5). Students with SED have prevalence rates of abusing 1 $(10.1 \%)$ or $2(4.0 \%)$ illicit drugs that are three to four times higher than students without SED. The rates of individual antisocial behaviors (range 4.1-20\%) and role impairments 
(range 2.8-19.9\%) were all higher among students with SED. Approximately $40 \%$ of students with SED have 1+ role impairment, roughly twice the amount as students without SED. All forms of peer victimization were significant higher among students with SED.

Table 5. Prevalence of Substance Abuse, Antisocial Behavior, and Role Impairments

\begin{tabular}{|lrlrl|}
\hline Characteristics $^{\mathbf{a}}$ & \multicolumn{2}{c}{ No SED (0-12) } & \multicolumn{2}{c|}{ SED (13+) } \\
\hline Substance Abuse & & & & \\
$\quad$ Cigarettes & 10.6 & $(10.4-10.6)$ & 23.4 & $(22.8-24.1)$ \\
$\quad$ Binge drinking & 8.6 & $(8.4-8.8)$ & 15.3 & $(14.7-15.9)$ \\
$\quad$ Marijuana & 7.6 & $(7.4-7.8)$ & 15.6 & $(15.0-16.2)$ \\
Illicit Drugs & & & & \\
$\quad 0$ & 96.2 & $(96.0-96.3)$ & 85.9 & $(85.3-86.5)$ \\
1 & 3.0 & $(2.9-3.1)$ & 10.1 & $(9.6-10.6)$ \\
$2+$ & 0.9 & $(0.8-1.0)$ & 4.0 & $(3.7-4.4)$ \\
Prescription Drugs & & & & \\
$\quad$ Opioids & 1.1 & $(1.0-1.2)$ & 4.1 & $(3.8-4.5)$ \\
$\quad$ Tranquilizers & 1.6 & $(1.5-1.7)$ & 5.7 & $(5.3-6.1)$ \\
Total impairments, No. & & & & \\
$\quad 0$ & 79.2 & $(78.9-80.0)$ & 59.4 & $(58.9-60.2)$ \\
$\quad$ & 10.6 & $(10.4-10.8)$ & 15.1 & $(14.5-15.7)$ \\
$\quad 2+$ & 10.2 & $(10.0-10.4)$ & 25.5 & $(24.8-26.2)$ \\
Antisocial behavior & & & & \\
$\quad$ Gun carrying & 6.1 & $(6.0-6.3)$ & 9.1 & $(9.0-9.2)$ \\
$\quad$ Drug dealing & 3.7 & $(3.6-3.8)$ & 8.7 & $(8.3-9.2)$ \\
Fighting & 7.9 & $(7.7-8.1)$ & 20.0 & $(19.4-20.7)$ \\
$\quad$ Being drunk at school & 6.8 & $(6.6-7.0)$ & 17.2 & $(16.6-17.8)$ \\
Peer victimization & & & & \\
$\quad$ Steal with force & 3.4 & $(3.3-3.5)$ & 12.2 & $(11.7-12.7)$ \\
$\quad$ Verbal threat & 18.1 & $(17.9-18.4)$ & 45.2 & $(44.4-46.0)$ \\
$\quad$ Physical threat & 24.1 & $(23.8-24.4)$ & 39.7 & $(38.9-40.5)$ \\
$\quad$ Sexual assault & 7.2 & $(7.0-7.4)$ & 24.3 & $(23.4-25.0)$ \\
\hline Values expressed as valid column percentage & $(95 \%$ confidence interval). \\
\hline
\end{tabular}

\section{Heterogeneity of SED}

A four-class model is the most parsimonious as the LMR-LRT indicates a fiveclass solution is not significantly better (Table 6). Four distinct subclasses emerge that vary by both symptom type and severity: mixed moderate risk, mixed high risk, anxious moderate risk, and depressed high risk. The moderate mixed $(\mathrm{M}=15.3, \mathrm{SD}=1.76)$ and anxious moderate $(\mathrm{M}=14.7, \mathrm{SD}=1.72)$ classes have lower means compared to the mixed high $(\mathrm{M}=23.4, \mathrm{SD}=1.38)$ and depressed high $(\mathrm{M}=17.9, \mathrm{SD}=2.65)$ classes. 
Table 6. Global Model Fit Statistics from Latent Class Analysis

\begin{tabular}{|lccc|}
\hline Model & Adjusted BIC & LMR-LRT $\boldsymbol{p}$-value & Entropy \\
\hline 1-Class & $242,825.11$ & - & - \\
2-Class & $218,815.67$ & $<0.0001$ & 0.877 \\
3-Class & $215,818.49$ & $<0.0001$ & 0.757 \\
4-Class & $214,098.23$ & 0.0082 & 0.715 \\
5-Class & $213,450.98$ & 0.8214 & 0.740 \\
\hline
\end{tabular}

Abbreviation: BIC, Bayesian information criterion; LMR-LRT, Lo-Mendell-Rubin likelihood ratio test $p$ value for $(K-1)$-classes.

Figure 4. Probability of endorsing most of the time and all of the time across subtypes.

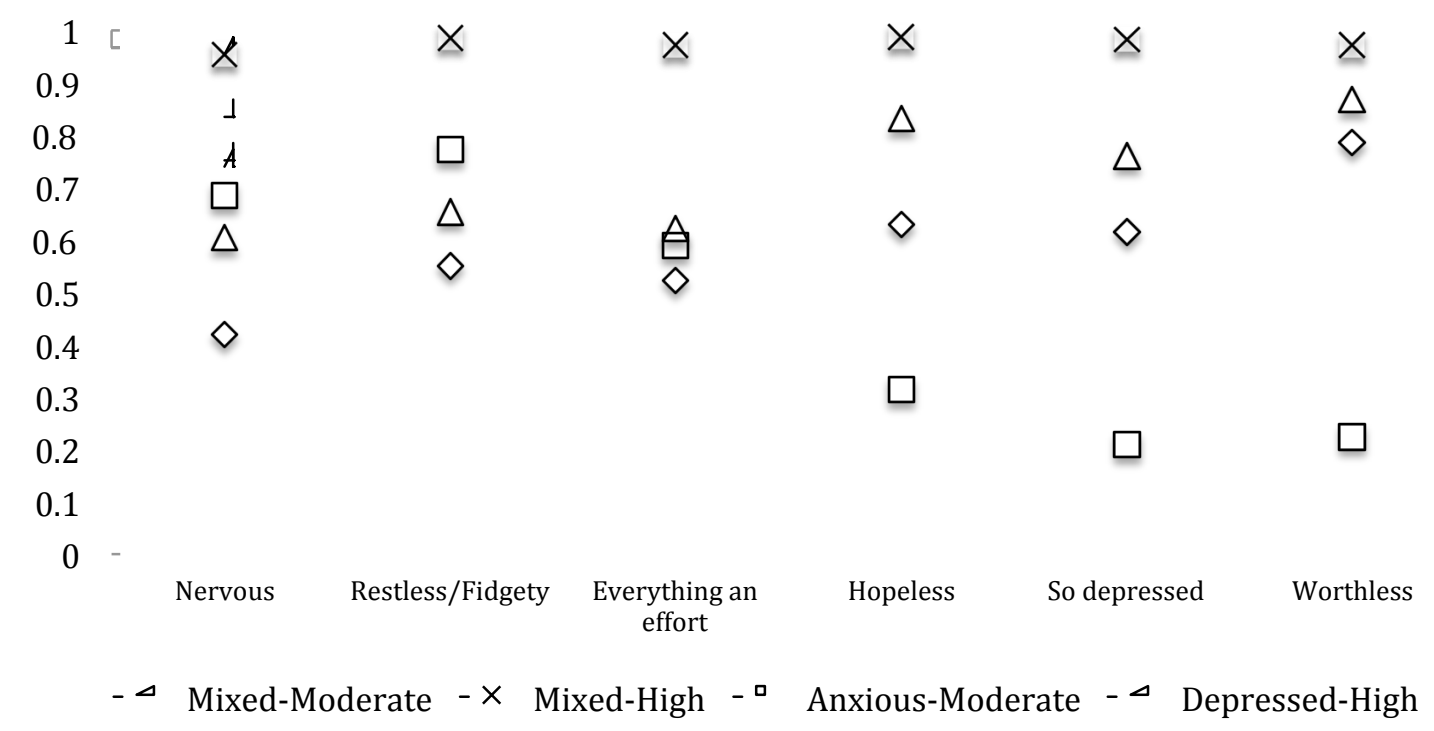

Among the mixed moderate class, the probabilities of endorsing most of the time or all of the time for hopeless (0.63), restless and fidgety (0.55), so depressed that nothing can cheer you up (0.62) and everything was an effort (0.52) are comparable, and the probability for worthless $(0.79)$ is the highest (Figure 4$)$. The probabilities for all items are significantly elevated for the mixed high class (range 0.95-0.99). In the anxious moderate class, the probabilities for nervous (0.69), restless and fidgety $(0.77)$, and everything was an effort (0.59) are higher than the three depression items (range 0.210.31). Although the probabilities are above 0.60 for all items among the depressed high class, hopeless (0.83), so depressed that nothing could cheer you up (0.76), and worthless (0.87) were higher than the three anxious symptoms (range 0.60-0.65). 
Table 7. Social and Demographic Characteristics of Subtypes

\begin{tabular}{|c|c|c|c|c|}
\hline Characteristics $^{\mathrm{a}}$ & Mixed Mod & Mixed High & Anx Mod & Depress High \\
\hline Overall & $29.1(28.4-29.8)$ & $22.4(21.8-23.1)$ & $18.0(17.4-18.6)$ & $30.5(29.8-31.2)$ \\
\hline \multicolumn{5}{|l|}{ Grade } \\
\hline 6 & $14.6(13.5-15.6)$ & $21.3(19.9-22.7)$ & $17.2(15.8-18.6)$ & $21.0(19.8-22.2)$ \\
\hline 8 & $27.5(26.2-28.9)$ & $22.9(21.6-24.4)$ & $23.7(22.2-25.4)$ & $30.1(28.8-31.4)$ \\
\hline 10 & $33.2(31.8-34.6)$ & $30.0(28.5-31.6)$ & $29.8(28.1-31.5)$ & $29.6(28.3-31.0)$ \\
\hline 12 & $24.7(23.5-26.0)$ & $25.8(24.4-27.3)$ & $29.3(27.6-31.2)$ & $19.3(18.2-20.5)$ \\
\hline \multicolumn{5}{|l|}{ Gender } \\
\hline Female & $66.7(65.3-68.2)$ & $47.3(45.6-49.1)$ & $65.2(63.4-67.1)$ & $66.2(64.8-67.6)$ \\
\hline Male & $33.3(31.8-34.7)$ & $52.3(50.9-54.4)$ & $34.8(32.9-36.6)$ & $33.8(32.4-35.2)$ \\
\hline \multicolumn{5}{|l|}{ Race/Ethnicity } \\
\hline White & $84.5(83.3-85.5)$ & $78.4(76.9-79.8)$ & $85.1(83.7-86.4)$ & $82.6(81.4-83.7)$ \\
\hline Black & $4.9(4.3-5.6)$ & $8.1(7.2-9.1)$ & $5.9(5.1-6.9)$ & $5.8(5.1-6.5)$ \\
\hline Hispanic & $3.2(2.7-3.8)$ & $3.5(2.9-4.1)$ & $2.7(2.1-3.3)$ & $3.6(3.1-4.2)$ \\
\hline AA/PI & $1.3(1.0-1.7)$ & $1.9(1.5-2.4)$ & $0.7(0.4-1.1)$ & $0.9(0.6-1.2)$ \\
\hline Other & $6.1(5.4-6.9)$ & $8.1(7.2-9.1)$ & $5.7(4.9-6.6)$ & $7.2(6.5-8.0)$ \\
\hline \multicolumn{5}{|l|}{ Biological Parents } \\
\hline 1 & $44.4(43.0-45.9)$ & $40.9(39.3-42.6)$ & $43.8(42.0-45.7)$ & $45.5(44.0-46.9)$ \\
\hline 2 & $42.5(41.0-44.0)$ & $43.7(42.0-45.4)$ & $44.2(42.3-46.1)$ & $40.0(38.3-41.1)$ \\
\hline Other & $13.1(12.1-14.1)$ & $15.4(14.2-16.7)$ & $12.0(10.8-13.2)$ & $14.8(13.8-15.9)$ \\
\hline \multicolumn{5}{|c|}{ Youth in Poverty (\%) } \\
\hline $10.7-20.9$ & $25.4(24.1-26.7)$ & $25.6(24.2-27.1)$ & $25.0(23.4-27.3)$ & $21.8(20.6-23.0)$ \\
\hline $21.1-24.6$ & $25.4(24.2-26.7)$ & $24.8(23.4-26.3)$ & $25.4(23.8-27.0)$ & $25.3(24.0-26.5)$ \\
\hline $25.1-30.7$ & $24.9(23.7-26.2)$ & $23.5(22.1-24.9)$ & $25.4(23.8-27.0)$ & $26.9(25.6-28.2)$ \\
\hline $30.9-52.8$ & $24.3(23.0-25.6)$ & $26.1(24.7-27.6)$ & $24.0(22.5-25.7)$ & $26.0(24.8-27.3)$ \\
\hline \multicolumn{5}{|l|}{ Population Density } \\
\hline $2,188-19,978$ & $23.9(22.6-25.2)$ & $25.1(23.6-26.5)$ & $24.8(23.2-26.4)$ & $25.2(24.0-26.5)$ \\
\hline $20,071-37,544$ & $24.0(22.8-25.3)$ & $25.2(23.8-26.7)$ & $23.5(21.9-25.1)$ & $24.4(23.2-25.7)$ \\
\hline $37,655-75,427$ & $25.8(24.5-27.1)$ & $23.9(22.5-25.3)$ & $27.5(25.9-29.3)$ & $26.6(25.3-27.9)$ \\
\hline $75,896-305,489$ & $26.4(25.1-27.7)$ & $25.9(24.4-27.4)$ & $24.2(22.7-25.9)$ & $23.8(22.6-25.0)$ \\
\hline
\end{tabular}

Abbreviation: AA/PI, Asian-American and Pacific Islander; Mixed-Mod, mixed-moderate risk; Anx-Mod, anxious-moderate risk; Depress-High, depressed-high risk.

${ }^{a}$ Values expressed as valid column percentage (95\% confidence interval).

Among students who screened positive for SED, the most prevalent subtypes were mixed moderate and depressed high (Table 7). Several grade, gender, and race differences are noted between classes. For grade, there is a similar distribution of $10^{\text {th }}$ graders in each class. Depressed high has the lowest prevalence of $12^{\text {th }}$ graders and the highest prevalence of $8^{\text {th }}$ graders, while mixed moderate has the lowest prevalence of $6^{\text {th }}$ graders and highest prevalence of $10^{\text {th }}$ graders. High mixed has a more even distribution of males and females than the other three classes that are predominantly female (range 65.2-66.7\%). High mixed also has the highest proportion of non-Whites $(21.6 \%)$ while 
the remaining classes tend to have comparable rates of Whites. Poverty status and population density are similar among classes.

Table 8. Substance Abuse, Antisocial Behavior, and Role Impairments Among Subtypes

\begin{tabular}{|c|c|c|c|c|}
\hline Characteristics $^{\mathrm{a}}$ & Mixed Mod & Mixed High & Anx Mod & Depress High \\
\hline \multicolumn{5}{|l|}{ Substance Abuse } \\
\hline Cigarettes & $23.0(21.8-24.3)$ & $24.9(23.5-26.4)$ & $20.1(18.6-21.7)$ & $24.7(23.5-26.0)$ \\
\hline Binge drinking & $12.9(11.9-13.9)$ & $20.6(19.3-22.1)$ & $12.3(11.1-13.6)$ & $15.5(14.4-16.5)$ \\
\hline Marijuana & $14.9(13.9-16.0)$ & $17.5(16.2-18.9)$ & $13.3(12.0-14.6)$ & $16.1(15.0-17.2)$ \\
\hline \multicolumn{5}{|l|}{ Illicit Drugs } \\
\hline 0 & $86.4(85.4-87.5)$ & $84.3(83.0-10.1)$ & $89.2(87.9-90.4)$ & $84.5(83.3-85.5)$ \\
\hline 1 & $10.3(9.4-11.3)$ & $10.1(9.1-11.3)$ & $7.7(6.7-8.8)$ & $11.3(10.4-12.3)$ \\
\hline $2+$ & $3.3(2.8-3.9)$ & $5.5(4.8-6.4)$ & $3.1(2.5-3.9)$ & $4.2(3.6-4.9)$ \\
\hline \multicolumn{5}{|l|}{ Prescription Drugs } \\
\hline Opioids & $3.9(3.4-4.5)$ & $5.1(4.4-5.9)$ & $3.8(3.1-4.6)$ & $3.8(3.3-4.4)$ \\
\hline Tranquilizers & $5.6(4.9-6.3)$ & $6.0(5.2-6.8)$ & $5.5(4.7-6.4)$ & $5.6(5.0-6.4)$ \\
\hline \multicolumn{5}{|c|}{ Antisocial Behaviors } \\
\hline Gun carrying & $7.2(6.5-8.0)$ & $12.7(11.6-13.9)$ & $8.1(7.1-9.2)$ & $9.5(8.6-10.3)$ \\
\hline Drug dealing & $7.6(6.9-8.5)$ & $11.2(10.2-12.3)$ & $8.1(9.2-9.3)$ & $8.2(7.4-9.0)$ \\
\hline Fighting & $17.3(16.2-18.5)$ & $22.5(21.1-23.9)$ & $16.4(15.1-17.9)$ & $23.0(21.8-24.2)$ \\
\hline Drunk at school & $16.3(15.2-17.4)$ & $18.7(17.4-20.1)$ & $14.5(13.2-15.8)$ & $18.5(17.4-19.6)$ \\
\hline \multicolumn{5}{|l|}{ Role Impairments } \\
\hline 0 & $63.8(62.4-65.3)$ & $52.6(50.9-54.4)$ & $66.1(64.2-67.9)$ & $56.0(54.5-57.5)$ \\
\hline 1 & $15.0(14.0-16.2)$ & $15.6(14.4-17.0)$ & $14.0(12.7-15.4)$ & $15.5(14.4-16.6)$ \\
\hline $2+$ & $21.1(20.0-22.4)$ & $31.7(30.1-33.4)$ & $19.9(18.4-21.5)$ & $28.5(27.2-30.0)$ \\
\hline \multicolumn{5}{|l|}{ Peer Victimization } \\
\hline Steal with force & $8.5(7.7-9.3)$ & $18.1(16.8-19.5)$ & $9.9(8.8-11.1)$ & $12.8(11.9-13.8)$ \\
\hline Verbal threat & $45.6(44.1-47.1)$ & $37.9(36.3-40.0)$ & $45.1(43.3-47.0)$ & $50.1(48.7-51.6)$ \\
\hline Physical threat & $40.0(38.5-41.4)$ & $33.9(32.3-35.5)$ & $41.3(40.0-43.2)$ & $42.8(41.4-44.2)$ \\
\hline Sexual assault & $22.3(21.1-23.5)$ & $26.3(24.9-27.9)$ & $20.8(19.3-22.4)$ & $26.9(25.7-28.2)$ \\
\hline
\end{tabular}

Abbreviation: SD, standard deviation; Mixed-Mod, mixed-moderate risk; Anx-Mod, anxious-moderate risk; Depress-High, depressed-high risk.

${ }^{a}$ Values expressed as valid column percentage (95\% confidence interval).

With regard to cigarette and marijuana abuse in the past 30 days, the rates are comparable among classes (Table 8). For binge drinking in the past two weeks, however, the highest rate is among mixed high (20.6\%). Mixed high and depressed high have the highest rates of abusing two or more illicit drugs in the past 12 months, although opioid and tranquilizer abuse in the past 12 months are similar across classes. Among antisocial behaviors, mixed high and depressed high again have the highest rates, although these differences are most pronounced for fighting at school in the past 12 months. For role impairments, each class has a similar prevalence of 1 impairment in the past 12 months, 
while mixed high and depressed high have the highest rates of $2+$ impairments. Lastly, experiencing physical threats and sexual assault in the past 12 months is fairly similar across classes. Mixed high has the highest rate of having personal items stolen with force (18.1\%) and lowest rate of experiencing verbal threats $(37.9 \%)$, while depressed high has the highest rate of experiencing verbal threats.

Table 9. Multinomial Logistic Regression Results Predicting Class Membership

\begin{tabular}{|c|c|c|c|c|}
\hline Characteristics $^{\text {a,b }}$ & Mixed Mod & Mixed High & Anx Mod & Depress High \\
\hline \multicolumn{5}{|l|}{ Grade } \\
\hline 6 & 1.00 & 1.00 & 1.00 & 1.00 \\
\hline 8 & $1.87(1.65-2.11)$ & $1.18(1.03-1.35)$ & $1.42(1.22-1.66)$ & $1.44(1.29-1.60)$ \\
\hline 10 & $2.57(2.28-2.91)$ & $1.59(1.39-1.82)$ & $2.32(2.00-2.69)$ & $1.60(1.42-1.79)$ \\
\hline 12 & $2.53(2.23-2.88)$ & $1.78(1.55-2.05)$ & $2.83(2.42-3.29)$ & $1.40(1.23-1.58)$ \\
\hline \multicolumn{5}{|l|}{ Gender } \\
\hline Male & 1.00 & 1.00 & 1.00 & 1.00 \\
\hline Female & $2.45(2.27-2.66)$ & $1.30(1.19-1.42)$ & $2.41(2.18-2.66)$ & $2.64(2.43-2.86)$ \\
\hline \multicolumn{5}{|l|}{ Race/Ethnicity } \\
\hline White & 1.00 & 1.00 & 1.00 & 1.00 \\
\hline Black & $0.69(0.58-0.82)$ & $1.13(0.95-1.34)$ & $0.83(0.68-1.02)$ & $0.85(0.73-1.01)$ \\
\hline Hispanic & $1.19(0.97-1.46)$ & $1.14(0.89-1.45)$ & $0.93(0.70-1.23)$ & $1.16(0.94-1.43)$ \\
\hline AA/PI & $1.10(0.78-1.55)$ & $1.80(1.30-2.51)$ & $0.57(0.32-1.02)$ & $0.90(0.60-1.33)$ \\
\hline Other & $1.19(1.01-1.39)$ & 1.41 (1.18-1.67) & $1.00(0.81-1.24)$ & $1.28(1.10-1.49)$ \\
\hline \multicolumn{5}{|l|}{ Biological Parents } \\
\hline 1 & $1.37(1.26-1.48)$ & $1.15(1.05-1.27)$ & 1.25 (1.13-1.38) & $1.33(1.23-1.44)$ \\
\hline 2 & 1.00 & 1.00 & 1.00 & 1.00 \\
\hline Other & $1.59(1.41-1.79)$ & 1.43 (1.25-1.64) & $1.38(1.19-1.61)$ & $1.61(1.43-1.81)$ \\
\hline \multicolumn{5}{|c|}{ Youth in Poverty (\%) } \\
\hline $10.7-20.9$ & 1.00 & 1.00 & 1.00 & 1.00 \\
\hline $21.1-24.6$ & $0.92(0.83-1.02)$ & $0.93(0.82-1.05)$ & $0.91(0.79-1.03)$ & $1.05(0.94-1.17)$ \\
\hline $25.1-30.7$ & $0.93(0.82-1.05)$ & $0.97(0.84-1.12)$ & $0.91(0.78-1.06)$ & $1.22(1.08-1.39)$ \\
\hline $30.9-52.8$ & $0.91(0.81-1.04)$ & $0.97(0.84-1.13)$ & $0.89(0.76-1.03)$ & $1.16(1.02-1.32)$ \\
\hline \multicolumn{5}{|l|}{ Substance Abuse } \\
\hline Cigarettes & $1.50(1.34-1.67)$ & $1.28(1.13-1.46)$ & $1.28(1.11-1.47)$ & $1.49(1.34-1.67)$ \\
\hline Binge drinking & $0.68(0.60-0.77)$ & $1.10(0.96-1.27)$ & $0.71(0.60-0.83)$ & $0.78(0.69-0.89)$ \\
\hline Marijuana & $0.97(0.84-1.11)$ & $0.98(0.84-1.15)$ & $0.87(0.73-1.05)$ & $1.02(0.89-1.17)$ \\
\hline \multicolumn{5}{|l|}{ Illicit Drugs } \\
\hline 1 & $2.09(1.82-2.41)$ & $1.89(1.60-2.23)$ & $1.71(1.42-2.07)$ & $2.05(1.79-2.35)$ \\
\hline $2+$ & $1.61(1.23-2.11)$ & $2.19(1.68-2.84)$ & $1.53(1.09-2.15)$ & $2.02(1.58-2.59)$ \\
\hline \multicolumn{5}{|l|}{ Prescription Drugs } \\
\hline Opioids & $1.13(0.89-1.44)$ & $1.07(0.82-1.39)$ & $1.23(0.91-1.66)$ & $0.97(0.76-1.24)$ \\
\hline Tranquilizers & $1.30(1.06-1.59)$ & $0.96(0.76-1.22)$ & $1.21(0.94-1.57)$ & $1.14(0.93-1.40)$ \\
\hline \multicolumn{5}{|l|}{ Antisocial Behavior } \\
\hline Gun carrying & $1.02(0.88-1.19)$ & $1.07(0.82-1.39)$ & $1.02(0.84-1.24)$ & $1.13(0.98-1.30)$ \\
\hline Drug dealing & $0.72(0.60-0.86)$ & $0.82(0.68-0.99)$ & $1.12(0.90-1.39)$ & $0.64(0.54-0.77)$ \\
\hline Fighting & $1.39(1.24-1.56)$ & $1.47(1.29-1.66)$ & $1.40(1.21-1.62)$ & $1.68(1.51-1.86)$ \\
\hline Drunk at school & $1.18(1.03-1.35)$ & $1.01(0.87-1.19)$ & $1.03(0.86-1.23)$ & $1.12(0.98-1.29)$ \\
\hline
\end{tabular}


Table 9. Continued

\begin{tabular}{|c|c|c|c|c|}
\hline Characteristics $^{\text {a,b }}$ & Mixed Mod & Mixed High & Anx Mod & Depress High \\
\hline \multicolumn{5}{|l|}{ Role Impairments } \\
\hline 1 & $1.31(1.17-1.46)$ & $1.58(1.39-1.80)$ & $1.29(1.11-1.48)$ & $1.44(1.28-1.60)$ \\
\hline $2+$ & $1.52(1.36-1.70)$ & $2.54(2.24-2.87)$ & $1.53(1.32-1.77)$ & $2.10(1.88-2.33)$ \\
\hline \multicolumn{5}{|l|}{ Peer Victimization } \\
\hline Steal with force & $1.08(0.93-1.26)$ & $3.22(2.78-3.72)$ & $1.44(1.21-1.72)$ & $1.41(1.23-1.61)$ \\
\hline Verbal threat & $2.46(2.26-2.69)$ & $1.31(1.17-1.48)$ & $2.61(2.33-2.91)$ & $2.64(2.41-2.88)$ \\
\hline Physical threat & $1.34(1.24-1.46)$ & $0.92(0.82-1.02)$ & $1.44(1.30-1.60)$ & $1.33(1.23-1.45)$ \\
\hline Sexual assault & $1.75(1.57-1.95)$ & $2.43(2.13-2.77)$ & $1.53(1.33-1.76)$ & $1.90(1.71-2.11)$ \\
\hline
\end{tabular}

Abbreviation: AA/PI, Asian-American and Pacific Islander; Mixed-Mod, mixed-moderate risk; Anx-Mod, anxious-moderate risk; Depress-High, depressed-high risk

${ }^{a}$ Values expressed as adjusted relative risk (95\% confidence interval).

${ }^{\mathrm{b}}$ Population density omitted from table due to lack of significant findings.

Table 9 shows the results from the multinomial logistic regression model predicting class membership with social and demographic characteristics, substance abuse, antisocial behaviors, role impairments, and peer victimization entered as predictors. Compared to $6^{\text {th }}$ graders, students in higher grades are significantly more likely to be in all classes, although the effects are strongest for mixed moderate and anxious moderate. Similarly, females are more likely to be in all classes, although the effect size for mixed high is noticeably weaker $(\mathrm{RR}=1.30,95 \% \mathrm{CI} 1.19-1.42)$. Compared to Whites, Blacks are significantly less likely to be mixed moderate $(\mathrm{RR}=0.69,95 \% \mathrm{CI}$ 0.58-0.82), while AA/PI are more likely to be mixed high ( $\mathrm{RR}=1.80,95 \% \mathrm{CI} 1.30-2.51)$ and Other races are more likely to be in mixed moderate $(\mathrm{RR}=1.19,95 \% \mathrm{CI} 1.01-1.39)$, mixed high $(\mathrm{RR}=1.41,95 \% \mathrm{CI} 1.18-1.67)$, and depressed high $(\mathrm{RR}=1.28,95 \% \mathrm{CI} 1.10$ 1.49). No significant race/ethnicity effects exist for anxious moderate. With the exception of depressed high, youth in poverty and population density are not significant predictors of class membership.

For substance abuse, students abusing cigarettes in the past 30 days are significantly more likely to belong to all classes, while students binge drinking in the past two weeks are significantly less likely to be in mixed moderate, anxious moderate, and 
depressed high. No significant effects are demonstrated for marijuana. Similarly, both types prescription drug abuse are not significant predictors of class membership, although students abusing tranquilizers in the past 12 months are significantly more likely to be mixed moderate ( $\mathrm{RR}=1.30,95 \% \mathrm{CI} 1.06-1.59)$. Abuse of illicit drugs in the past 12 months is a significant predictor for all classes. For $2+$ illicit drugs, however, the effects are more pronounced for mixed high $(\mathrm{RR}=2.19,95 \% \mathrm{CI} 1.68-2.84)$ and depressed high $(\mathrm{RR}=2.02,95 \% \mathrm{CI} 1.58-2.59)$.

Among antisocial behaviors in the past 12 months, fighting is associated with a significantly increased likelihood of class membership and students reporting drug dealing are significantly less likely to be in mixed moderate, mixed high, and depressed high. Students with role impairments in the past 12 months are significantly more likely to belong to all classes, although the effects are strongest for mixed high and depressed high. Similarly, all forms of peer victimization in the past 12 months predict class membership, although stealing with force does not emerge as a predictor for mixed moderate. 


\section{CHAPTER IV}

\section{DISCUSSION}

The results indicate that the K6 performs well as a general screening scale for SED in a school-based epidemiologic survey. The distribution of K6 scores revealed approximately half of students scored $0-3$, a finding that is fairly comparable to a previous study that found the majority of respondents $(51.3 \%)$ scored $0-2 .^{22}$ Principal axis factor analysis found a strong first factor and no evidence of a meaningful second factor with eigenvalues of 4.6 and 0.5 , respectively. ${ }^{7}$ This is highly consistent with the NCS-A sample that yielded values of 3.6 and $0.7 .^{22}$ CFA also demonstrated the unidimensional structure of the K6, although optimal fit was only achieved after correlated residuals were further specified in models. This relationship, however, makes sense as the items all constitute the interrelated aspects of non-specific SPD. Moreover, a recent analysis of K6 data from the Canadian National Population Health Survey $(n=7,259)$ found optimal global fit statistics only when correlated residuals were specified. ${ }^{82}$

While the 30 -day prevalence of $13.9 \%$ falls within the range (4-14\%) found in other studies, ${ }^{1,32}$ this is over double the 30 -day rate of $5.6 \%$ estimated in the NCS-A school sample. ${ }^{17}$ This national estimate, however, was derived using a two-level multilevel Bayes model with binary outcomes, so it is likely the unweighted scoring algorithm used in this study does not fully capture core aspects of SED that lead to more

accurate estimates (i.e., behavior disorders and role impairments). ${ }^{17,22,32}$ Combining the K6 scoring algorithm with one or more impairments (i.e., suspension, arrests, and 
substance-related consequences), however, yielded a prevalence rate of $6.7 \%$ that is comparable to the national estimate and consistent with elevated psychiatric morbidity among Kentucky youth. ${ }^{10,11}$

Several social and demographic factors were significant predictors of SED. In particular, $10^{\text {th }}$ graders had the highest relative risk of SED, consistent with the significantly increased odds $(\mathrm{OR}=1.5,95 \% \mathrm{CI} 1.1-2.2)$ among 16 year olds in the NCSA. ${ }^{32}$ The findings for number of biological parents were also highly significant predictors in both the KIP and NCS-A samples. ${ }^{32}$ Females were at significantly increased risk of SED in the KIP, but not in the NCS-A sample (OR=1.0, 95\%CI 0.8-1.2). ${ }^{32}$ No significant effects were found for Blacks and AA/PI, also consistent with the NCS-A, although Hispanics $(\mathrm{RR}=1.12,95 \% \mathrm{CI} 1.01-1.23)$ and Other races $(\mathrm{RR}=1.45,95 \% \mathrm{CI} 1.35-1.55)$ were at elevated risk. In the NCS-A, Blacks were significantly less likely to have SED $(\mathrm{OR}=0.60,95 \% \mathrm{CI} 0.4-0.9)$ while no effects were found for any other race, although Hispanics had an increased, albeit insignificant, odds (OR=1.4, 95\%CI 0.7-2.6). ${ }^{32}$ The null effects for youth in poverty and population density were highly similar to the NCS-A that found no effects for family income, Census region, and urbanicity. ${ }^{32}$ The high rates of substance abuse, antisocial behavior, and role impairments among students with SED are broadly comparable to evidence from previous studies that suggest multivariate disorder profiles are more relevant than social and demographic predictors, especially since associations with social and demographic factors tend to become insignificant when severity and number of disorders are included as controls in estimates. ${ }^{32}$

While it was not possible in this study to make inferences about multimorbidity using DSM diagnoses, the heterogeneous set of SED subclasses derived from LCA were 
characterized by differences in both severity and symptom type. This is consistent with some research, ${ }^{70,83}$ although a multitude of LCA studies have found heterogeneity with regard to either severity or symptom type, but not both. ${ }^{64-69,71}$ These studies have typically explored heterogeneity in the structure of major depression and anxiety disorders, while this analysis looked at SED. To date, however, no studies have employed LCA to evaluate the heterogeneity of SED as measured by the K6.

Previous studies have found behavioral and somatic symptoms of depression are more common, and psychomotor symptoms less common, in children and adolescents than adults. ${ }^{58,59,61-63}$ This is somewhat consistent with the findings in this study that found a depressed subtype with high probabilities of endorsing most of the time or all of the time for feeling hopeless, so depressed nothing could cheer you up, and worthless. Fighting and 2+ role impairments were also significant predictors of class membership, consistent with previous studies. ${ }^{22,32}$ In the NCS-A, however, typical and atypical subtypes of major depression among adolescents differed by symptoms of appetite, weight loss, and feelings of guilt, suggesting further heterogeneity that may not have been fully captured in this study. ${ }^{70}$

As the $\mathrm{K} 6$ is best able to detect mood and anxiety disorders in adolescents and adults, ${ }^{7,21,32}$ evidence from a LCA of NCS data suggests comorbid MDD and GAD do not emerge from mutually exclusive classifications, but from a heterogeneous set of clinically meaningful classes characterized by overlapping symptoms that further vary by severity and persistence. ${ }^{83}$ The mixed classes found in this study support this notion as these two classes tended to endorse most of the time or all of the time for all items, with the highest probabilities being found for mixed high. With regard to anxiety disorders, a 
LCA of adolescents with lifetime anxiety disorders found classes were better characterized by disorder type than severity or number of anxiety disorders. ${ }^{69}$ This particular finding is somewhat consistent with the anxious moderate risk class characterized by the three anxiety symptoms and lower K6 scores, although elevated rates of impairment, service utilization, and comorbid mood disorders were also found among adolescents with GAD and social phobia compared to other anxiety disorders. ${ }^{69}$ Moreover, anxious moderate was the smallest class (18\% of SED cases), which is somewhat consistent with the NCS-A finding of approximately $11 \%$ of SED cases being comprised of anxiety disorders. ${ }^{32}$ While the K6 is unable to differentiate between anxiety disorders, it remains possible anxiety symptoms may be more salient for a small subset of SED cases despite having similar features of disordered behavior, role impairments, and comorbid depressive symptoms. Taken together, differentiating between SED cases using the $\mathrm{K} 6$ provides additional evidence that both symptom severity and type may be more relevant than the specific types of disorders that may comprise the SED. ${ }^{1,28,32,69,70}$

\section{Limitations}

Although the present study confirms the factor structure of the $\mathrm{K} 6$, provides estimates and correlates of SED, and elucidates on the heterogeneity of SED using LCA, several limitations merit discussion. First, data from the KIP are cross-sectional. Temporality between SED, class membership, and significant predictors therefore cannot be inferred. The results from this study are nonetheless consistent with findings from the NCS-A and other population-based studies of adolescents. ${ }^{1,32}$ Second, while the distribution of $\mathrm{K} 6$ scores is fairly similar to that found in the NCS-A, ${ }^{22}$ approximately $2.4 \%$ of students answered all of the time for each item. This raises the question as to 
whether these students actually have maximum scores or if methodological issues influenced these item responses. Since the KIP is a self-report survey with very limited space, the K6 was placed at the end of the 2012 instrument, raising the possibility that fatigue may have introduced biased responses that artificially drove the prevalence to the higher end of the range found in previous studies. Similarly, all students who scored 24 were in the mixed high-risk class and had the highest rates of lifetime Zycopan abuse, a fictitious drug included on the KIP to detect social desirability. While virtually identical distributions and effects of included predictors were produced when these students were censored from the mixed high class, fatigue and social desirability cannot be fully ruled out as forms of differential misclassification bias.

Given that the vast majority of Kentucky students included in this study were White (84\%), these results may not generalize to other populations or states. It is also possible the large analytic subsample of the $2012 \operatorname{KIP}(n=108,736)$ may have led to erroneously significant estimates that provide limited utility for prevention efforts. Although this study demonstrated several social and demographic predictors of SED, comorbidity and heterogeneity tend to be more relevant than social and demographic predispositions. ${ }^{5,28,32}$ The significant effects found for cigarette smoking, illicit drug abuse, role impairments, and peer victimization support this view and remain highly consistent with previous studies. ${ }^{26,28,30,32,40,43,84}$

With regard to the LCA, the preponderance of higher grades and females among classes suggests future studies that stratify by grade and gender may be necessary. This is particularly relevant as rates of substance abuse, prescription and illicit drug abuse, antisocial behavior, role impairments, and peer victimization have all been shown to vary 
by age and gender. $1,5,27,28,30,32,84-87$ The roughly equal distribution of classes also raises the issue of whether the heterogeneity of SED represents true population-based differences or a methodological artifact. Given the larger effects found for illicit drug abuse, fighting, and role impairments among the more severe classes, however, these results suggest SED subtypes may be effectively distinguished in community samples of adolescents. ${ }^{70}$ Companion LCA studies that evaluate the heterogeneity of K6 responses among adolescents will be necessary to confirm findings from this study.

Lastly, the dichotomized scoring of the K6 may have influenced the precision of estimates. In the NCS-A, the sensitivity of the K6 cut-point that maximizes concordance with SED estimates was only $34 \%$ and only $32 \%$ of K6 positive cases received a positive DSM diagnosis (i.e., positive predictive value).$^{22}$ These values are unacceptably low, which has prompted the use of polychotomous scoring rules that yield more optimal classification functions and precise estimates. ${ }^{88-90}$ Other studies have augmented the K6 with questions about behavior disorders and fit multi-level models to predict school-level SED to increase precision. ${ }^{17,22}$ These sorts of approaches, however, require diagnostic data and are therefore beyond the scope of this study as KIP data are primarily used for policy and planning purposes as opposed to identifying clinical cases. Moreover, the KIP does not contain validated instruments to measure behavior disorders and role impairments, although it is worth noting again that combining the unweighted K6 scoring algorithm with $1+$ role impairments produced a more conservative estimate of $6.7 \%$.

\section{Implications}

As the SEOW emphasizes the overlap between substance abuse and psychiatric morbidity, the inclusion of the K6 on the KIP provides additional evidence of its utility as 
a brief and valid screener for SED. While the K6 appears to be less relevant for identifying individual cases meeting clinical criteria, it is particularly useful for inclusion in large epidemiologic surveys like the KIP that have limited space and logistics that demand timely administration. ${ }^{17,22}$ The inclusion of the K6 on the KIP also falls in line with recent recommendations by the President's New Freedom Commission on Mental Health, the Department for Health and Human Services, and the Institute for Medicine for schools to improve their early identification and prevention efforts. ${ }^{91}$ Thus, epidemiologic data like those generated by the K6 may inform the development and allocation of school-based resources to facilitate more rapid referrals and service utilization. ${ }^{91,92}$

This is highly relevant to a rural and impoverished state like Kentucky as students with SED as well as substance use and behavior disorders are more likely to access mental health services when their schools are located in urban, compared to rural, environments. ${ }^{91,93,94}$ Interestingly, a recent NCS-A study suggests increased delivery of counseling in schools is associated with decreased service utilization among youth with SED while prevention activities are associated with increased utilization. ${ }^{91}$ While these findings were derived from a national sample of schools and may not necessarily generalize to Kentucky schools, the provision of prevention activities throughout the state has been shown to influence recent decreases in the state and regional rates of adolescent substance abuse, suicide behaviors, and other high-risk behaviors. ${ }^{10,11,95}$

The impact of heterogeneity and comorbidity also has implications for prevention activities. As SED subtypes vary by symptom severity and type, factors like service utilization, treatment response, disorder onset, and recurrence also vary. ${ }^{96-100}$ 
Specific timing patterns in the onset of psychiatric morbidity and the influence of onset on subsequent disorders have also been shown. ${ }^{25}$ Nearly all selective and universal anxiety prevention programs target youth during adolescence, despite evidence suggesting that clinically significant anxiety may present during childhood. ${ }^{101}$ To delay or halt progression of psychiatric morbidity in adolescence and adulthood, the main role of prevention activities may benefit from shifting focus from disorder-specific interventions to addressing the core features of SED among youth (i.e., psychological distress, disordered behavior, role impairments, and multimorbidity). ${ }^{1,28,32,86,102}$ Based upon the presentation of comorbid features along with other relevant risk and protective factors, prevention programs may also benefit from identifying critical periods to intervene as well as tailoring activities to varying levels of severity. Furthermore, the stability of subtypes has been shown to be low in adolescents, with large proportions cycling from one subtype to another over time. ${ }^{61,103-105}$ Because of this instability, longitudinal research is necessary to identify the continuity, correlates, and timing of subtype changes. $^{70}$

Considering the findings of this dissertation with the research base, the next steps include validation of the $\mathrm{K} 6$ on other state surveys that use school and community-based samples of adolescents, generation of cross-state comparisons, and the implementation of validated statistical approaches to generate more precise SED estimates, especially in circumstances where gold standard diagnoses are not available. The planned inclusion of questions pertaining to suicide behaviors, bully victimization, and new drugs of abuse on the 2014 KIP also provides additional opportunity to explore issues related to SED and its heterogeneity. Thus, this dissertation provides a foundation for increased epidemiologic 
infrastructure in Kentucky through the timely surveillance of child and adolescent SED as measured by the $\mathrm{K} 6$. 


\section{REFERENCES}

1. Merikangas KR, Nakamura EF, Kessler RC. Epidemiology of mental disorders in children and adolescents. Dialogues Clin Neurosci. 2009;11(1):7-20.

2. Robins LN, Wing J, Wittchen HU, Helzer JE, Babor TF, Burke J, Farmer A, Jablenski A, Pickens R, Regier DA, et al. The Composite International Diagnostic Interview. An epidemiologic Instrument suitable for use in conjunction with different diagnostic systems and in different cultures. Arch Gen Psychiatry. 1988;45(12):1069-1077.

3. Haro JM, Arbabzadeh-Bouchez S, Brugha TS, de Girolamo G, Guyer ME, Jin R, Lepine JP, Mazzi F, Reneses B, Vilagut G, Sampson NA, Kessler RC. Concordance of the Composite International Diagnostic Interview Version 3.0 (CIDI 3.0) with standardized clinical assessments in the WHO World Mental Health surveys. Int J Methods Psychiatr Res. 2006;15(4):167-180.

4. Kessler RC. Epidemiological perspectives for the development of future diagnostic systems. Psychopathology. 2002;35(2-3):158-161.

5. Kessler RC, Chiu WT, Demler O, Merikangas KR, Walters EE. Prevalence, severity, and comorbidity of 12-month DSM-IV disorders in the National Comorbidity Survey Replication. Arch Gen Psychiatry. 2005;62(6):617-627.

6. Demyttenaere K, Bruffaerts R, Posada-Villa J, Gasquet I, Kovess V, Lepine JP, Angermeyer MC, Bernert S, de Girolamo G, Morosini P, Polidori G, Kikkawa T, Kawakami N, Ono Y, Takeshima T, Uda H, Karam EG, Fayyad JA, Karam AN, Mneimneh ZN, Medina-Mora ME, Borges G, Lara C, de Graaf R, Ormel J, Gureje O, Shen Y, Huang Y, Zhang M, Alonso J, Haro JM, Vilagut G, Bromet EJ, Gluzman S, Webb C, Kessler RC, Merikangas KR, Anthony JC, Von Korff MR, Wang PS, Brugha TS, Aguilar-Gaxiola S, Lee S, Heeringa S, Pennell BE, Zaslavsky AM, Ustun TB, Chatterji S, Consortium WHOWMHS. Prevalence, severity, and unmet need for treatment of mental disorders in the World Health Organization World Mental Health Surveys. JAMA. 2004;291(21):2581-2590.

7. Kessler RC, Green JG, Gruber MJ, Sampson NA, Bromet E, Cuitan M, Furukawa TA, Gureje O, Hinkov H, Hu CY, Lara C, Lee S, Mneimneh Z, Myer L, OakleyBrowne M, Posada-Villa J, Sagar R, Viana MC, Zaslavsky AM. Screening for serious mental illness in the general population with the K6 screening scale: results from the WHO World Mental Health (WMH) survey initiative. Int J Methods Psychiatr Res. 2010;19 Suppl 1:4-22.

8. Piper D, Stein-Seroussi A, Flewelling R, Orwin RG, Buchanan R. Assessing state substance abuse prevention infrastructure through the lens of CSAP's Strategic Prevention Framework. Eval Program Plann. 2012;35(1):66-77.

9. Florin P, Friend KB, Buka S, Egan C, Barovier L, Amodei B. The interactive systems framework applied to the strategic prevention framework: the Rhode Island experience. Am J Community Psychol. 2012;50(3-4):402-414. 
10. Preventing substance abuse and mental illness in Kentucky: a state profile to promote positive mental and behavior health: Substance Abuse and Mental Health Services Administration; 2011.

11. Preventing substance abuse and mental illness in Kentucky: an updated state profile: Substance Abuse and Mental Health Services Administration; 2012.

12. Shaffer D, Scott M, Wilcox H, Maslow C, Hicks R, Lucas CP, Garfinkel R, Greenwald S. The Columbia Suicide Screen: validity and reliability of a screen for youth suicide and depression. J Am Acad Child Adolesc Psychiatry. 2004;43(1):71-79.

13. Levitt J, Saka N, Romanelli LH, Hoagwood K. Early identification of mental health problems in schools: the status of implementation. J School Psychol. 2007;45:163-191.

14. Glover TA, Albers CA. Considerations for evaluating universal screening assessments. J School Psychol. 2007;45:117-135.

15. Leaf PJ, Alegria M, Cohen P, Goodman SH, Horwitz SM, Hoven CW, Narrow WE, Vaden-Kiernan M, Regier DA. Mental health service use in the community and schools: results from the four-community MECA Study. Methods for the Epidemiology of Child and Adolescent Mental Disorders Study. J Am Acad Child Adolesc Psychiatry. 1996;35(7):889-897.

16. Burns BJ, Costello EJ, Angold A, Tweed D, Stangl D, Farmer EM, Erkanli A. Children's mental health service use across service sectors. Health Aff (Millwood). 1995;14(3):147-159.

17. Li F, Green JG, Kessler RC, Zaslavsky AM. Estimating prevalence of serious emotional disturbance in schools using a brief screening scale. Int J Methods Psychiatr Res. 2010;19 Suppl 1:88-98.

18. Dohrenwend BP, Shrout PE, Egri G, Mendelsohn FS. Nonspecific psychological distress and other dimensions of psychopathology. Measures for use in the general population. Arch Gen Psychiatry. 1980;37(11):1229-1236.

19. Vernon SW, Roberts RE. Measuring nonspecific psychological distress and other dimensions of psychopathology. Further observations on the problem. Arch Gen Psychiatry. 1981;38(11):1239-1247.

20. Kessler RC, Andrews G, Colpe LJ, Hiripi E, Mroczek DK, Normand SL, Walters EE, Zaslavsky AM. Short screening scales to monitor population prevalences and trends in non-specific psychological distress. Psychol Med. 2002;32(6):959-976.

21. Kessler RC, Barker PR, Colpe LJ, Epstein JF, Gfroerer JC, Hiripi E, Howes MJ, Normand SL, Manderscheid RW, Walters EE, Zaslavsky AM. Screening for serious mental illness in the general population. Arch Gen Psychiatry. 2003;60(2):184-189.

22. Green JG, Gruber MJ, Sampson NA, Zaslavsky AM, Kessler RC. Improving the K6 short scale to predict serious emotional disturbance in adolescents in the USA. Int J Methods Psychiatr Res. 2010;19 Suppl 1:23-35.

23. Schwartz S, Susser E. Commentary: what can epidemiology accomplish? Int J Epidemiol. 2006;35(3):587-590; discussion 593-586.

24. Weich S, Araya R. International and regional variation in the prevalence of common mental disorders: do we need more surveys? Br J Psychiatry. 2004; 184:289-290. 
25. Costello EJ, Foley DL, Angold A. 10-year research update review: the epidemiology of child and adolescent psychiatric disorders: II. Developmental epidemiology. J Am Acad Child Adolesc Psychiatry. 2006;45(1):8-25.

26. Merikangas KR, He JP, Burstein M, Swanson SA, Avenevoli S, Cui L, Benjet C, Georgiades K, Swendsen J. Lifetime prevalence of mental disorders in U.S. adolescents: results from the National Comorbidity Survey Replication-Adolescent Supplement (NCS-A). J Am Acad Child Adolesc Psychiatry. 2010;49(10):980-989.

27. Kessler RC, Berglund P, Demler O, Jin R, Merikangas KR, Walters EE. Lifetime prevalence and age-of-onset distributions of DSM-IV disorders in the National Comorbidity Survey Replication. Arch Gen Psychiatry. 2005;62(6):593-602.

28. Kessler RC, Avenevoli S, McLaughlin KA, Green JG, Lakoma MD, Petukhova M, Pine DS, Sampson NA, Zaslavsky AM, Merikangas KR. Lifetime comorbidity of DSM-IV disorders in the US National Comorbidity Survey Replication Adolescent Supplement (NCS-A). Psychol Med. 2012:1-14.

29. Brauner CB, Stephens CB. Estimating the prevalence of early childhood serious emotional/behavioral disorders: challenges and recommendations. Public Health Rep. 2006;121(3):303-310.

30. Kessler RC, Avenevoli S, Costello EJ, Georgiades K, Green JG, Gruber MJ, He JP, Koretz D, McLaughlin KA, Petukhova M, Sampson NA, Zaslavsky AM, Merikangas KR. Prevalence, persistence, and sociodemographic correlates of DSM-IV disorders in the National Comorbidity Survey Replication Adolescent Supplement. Arch Gen Psychiatry. 2012;69(4):372-380.

31. Diagnostic and Statistical Manual of Mental Disorders (4th ed., text rev.). Washington, DC; 2000.

32. Kessler RC, Avenevoli S, Costello J, Green JG, Gruber MJ, McLaughlin KA, Petukhova M, Sampson NA, Zaslavsky AM, Merikangas KR. Severity of 12month DSM-IV disorders in the National Comorbidity Survey Replication Adolescent Supplement. Arch Gen Psychiatry. 2012;69(4):381-389.

33. Angold A, Erkanli A, Farmer EM, Fairbank JA, Burns BJ, Keeler G, Costello EJ. Psychiatric disorder, impairment, and service use in rural African American and white youth. Arch Gen Psychiatry. 2002;59(10):893-901.

34. Canino G, Shrout PE, Rubio-Stipec M, Bird HR, Bravo M, Ramirez R, Chavez L, Alegria M, Bauermeister JJ, Hohmann A, Ribera J, Garcia P, Martinez-Taboas A. The DSM-IV rates of child and adolescent disorders in Puerto Rico: prevalence, correlates, service use, and the effects of impairment. Arch Gen Psychiatry. 2004;61(1):85-93.

35. Roberts RE, Roberts CR, Xing Y. Rates of DSM-IV psychiatric disorders among adolescents in a large metropolitan area. J Psychiatr Res. 2007;41(11):959-967.

36. Froehlich TE, Lanphear BP, Epstein JN, Barbaresi WJ, Katusic SK, Kahn RS. Prevalence, recognition, and treatment of attention-deficit/hyperactivity disorder in a national sample of US children. Arch Pediatr Adolesc Med. 2007;161(9):857864.

37. Cohen P, Cohen J, Kasen S, Velez CN, Hartmark C, Johnson J, Rojas M, Brook J, Streuning EL. An epidemiological study of disorders in late childhood and 
adolescence--I. Age- and gender-specific prevalence. J Child Psychol Psychiatry. 1993;34(6):851-867.

38. Loeber R, Burke JD, Lahey BB, Winters A, Zera M. Oppositional defiant and conduct disorder: a review of the past 10 years, part I. J Am Acad Child Adolesc Psychiatry. 2000;39(12):1468-1484.

39. Fergusson DM, Horwood LJ, Lynskey MT. Prevalence and comorbidity of DSMIII-R diagnoses in a birth cohort of 15 year olds. J Am Acad Child Adolesc Psychiatry. 1993;32(6):1127-1134.

40. Swendsen J, Burstein M, Case B, Conway KP, Dierker L, He J, Merikangas KR. Use and abuse of alcohol and illicit drugs in US adolescents: results of the National Comorbidity Survey-Adolescent Supplement. Arch Gen Psychiatry. 2012;69(4):390-398.

41. Compton WM, Thomas YF, Stinson FS, Grant BF. Prevalence, correlates, disability, and comorbidity of DSM-IV drug abuse and dependence in the United States: results from the national epidemiologic survey on alcohol and related conditions. Arch Gen Psychiatry. 2007;64(5):566-576.

42. Hasin DS, Stinson FS, Ogburn E, Grant BF. Prevalence, correlates, disability, and comorbidity of DSM-IV alcohol abuse and dependence in the United States: results from the National Epidemiologic Survey on Alcohol and Related Conditions. Arch Gen Psychiatry. 2007;64(7):830-842.

43. Kalaydjian A, Swendsen J, Chiu WT, Dierker L, Degenhardt L, Glantz M, Merikangas KR, Sampson N, Kessler R. Sociodemographic predictors of transitions across stages of alcohol use, disorders, and remission in the National Comorbidity Survey Replication. Compr Psychiatry. 2009;50(4):299-306.

44. Swendsen J, Anthony JC, Conway KP, Degenhardt L, Dierker L, Glantz M, He J, Kalaydjian A, Kessler RC, Sampson N, Merikangas KR. Improving targets for the prevention of drug use disorders: sociodemographic predictors of transitions across drug use stages in the national comorbidity survey replication. Prev Med. 2008;47(6):629-634.

45. Substance Abuse and Mental Health Services Administration OoAS. 2010-2011 National Survey on Drug Use and Health Model-Based Estimates (50 States and the District of Columbia). http://www.samhsa.gov/data/NSDUH/2k11State/NSDUHsaeTables2011.pdf. Accessed September 19, 2013.

46. Substance Abuse and Mental Health Services Administration OoAS. 2008-2010 National Survey on Drug Use and Health: Overview and Summary of Substate Region Estimation Methodology. http://www.samhsa.gov/data/NSDUH/substate2k10/Methodology/NSDUHsubstat eMethodology2010.htm. Accessed September 20, 2013.

47. Hudson CG. Validation of a model for estimating state and local prevalence of serious mental illness. Int J Methods Psychiatr Res. 2009;18(4):251-264.

48. Eaton DK, Kann L, Kinchen S, Shanklin S, Flint KH, Hawkins J, Harris WA, Lowry R, McManus T, Chyen D, Whittle L, Lim C, Wechsler H, Centers for Disease C, Prevention. Youth risk behavior surveillance - United States, 2011. MMWR Surveill Summ. 2012;61(4):1-162. 
49. Eaton DK, Kann L, Kinchen S, Shanklin S, Ross J, Hawkins J, Harris WA, Lowry R, McManus T, Chyen D, Lim C, Whittle L, Brener ND, Wechsler H. Youth risk behavior surveillance - United States, 2009. MMWR Surveill Summ. 2010;59(5):1142.

50. Regier DA, Kaelber CT, Rae DS, Farmer ME, Knauper B, Kessler RC, Norquist GS. Limitations of diagnostic criteria and assessment instruments for mental disorders. Implications for research and policy. Arch Gen Psychiatry. 1998;55(2):109-115.

51. Shaffer D, Fisher P, Dulcan MK, Davies M, Piacentini J, Schwab-Stone ME, Lahey BB, Bourdon K, Jensen PS, Bird HR, Canino G, Regier DA. The NIMH Diagnostic Interview Schedule for Children Version 2.3 (DISC-2.3): description, acceptability, prevalence rates, and performance in the MECA Study. Methods for the Epidemiology of Child and Adolescent Mental Disorders Study. J Am Acad Child Adolesc Psychiatry. 1996;35(7):865-877.

52. Newman DL, Moffitt TE, Caspi A, Magdol L, Silva PA, Stanton WR. Psychiatric disorder in a birth cohort of young adults: prevalence, comorbidity, clinical significance, and new case incidence from ages 11 to 21. J Consult Clin Psychol. 1996;64(3):552-562.

53. Caron C, Rutter M. Comorbidity in child psychopathology: concepts, issues and research strategies. J Child Psychol Psychiatry. 1991;32(7):1063-1080.

54. Costello EJ, Egger HL, Angold A. The developmental epidemiology of anxiety disorders: phenomenology, prevalence, and comorbidity. Child Adolesc Psychiatr Clin N Am. 2005;14(4):631-648, vii.

55. Saavedra JM, Silverman WK. Classification of anxiety disorders in children: what a difference two decades make. International Review of Psychiatry. 2002;14(2):87-101.

56. Weems CF, Stickle TR. Anxiety disorders in childhood: casting a nomological net. Clin Child Fam Psychol Rev. 2005;8(2):107-134.

57. Muthen B, Muthen LK. Integrating person-centered and variable-centered analyses: growth mixture modeling with latent trajectory classes. Alcohol Clin Exp Res. 2000;24(6):882-891.

58. Ryan ND, Puig-Antich J, Ambrosini P, Rabinovich H, Robinson D, Nelson B, Iyengar S, Twomey J. The clinical picture of major depression in children and adolescents. Arch Gen Psychiatry. 1987;44(10):854-861.

59. Strober M, Green J, Carlson G. Phenomenology and subtypes of major depressive disorder in adolescence. J Affect Disord. 1981;3(3):281-290.

60. Weiss B, Garber J. Developmental differences in the phenomenology of depression. Dev Psychopathol. 2003;15(2):403-430.

61. Roberts RE, Lewinsohn PM, Seeley JR. Symptoms of DSM-III-R major depression in adolescence: evidence from an epidemiological survey. $J$ Am Acad Child Adolesc Psychiatry. 1995;34(12):1608-1617.

62. Carlson GA, Kashani JH. Phenomenology of major depression from childhood through adulthood: analysis of three studies. Am J Psychiatry.

1988;145(10):1222-1225. 
63. Kovacs M. Presentation and course of major depressive disorder during childhood and later years of the life span. J Am Acad Child Adolesc Psychiatry. 1996;35(6):705-715.

64. Wadsworth ME, Hudziak JJ, Heath AC, Achenbach TM. Latent class analysis of child behavior checklist anxiety/depression in children and adolescents. $J$ Am Acad Child Adolesc Psychiatry. 2001;40(1):106-114.

65. Ferdinand RF, van Lang ND, Ormel J, Verhulst FC. No distinctions between different types of anxiety symptoms in pre-adolescents from the general population. J Anxiety Disord. 2006;20(2):207-221.

66. Williams S, Dahan J, Silverman WK, Pettit JW. Heterogeneous classes of cooccurring externalizing symptoms in a sample of youth referred for anxiety disorders. J Anxiety Disord. 2013;27(3):340-346.

67. Mezulis A, Stoep AV, Stone AL, McCauley E. A latent class analysis of depressive and externalizing symptoms in nonreferred adolescents. . Journal of Emotional and Behavioral Disorders. 2011;19(4):247-256.

68. Ferdinand RF, de Nijs PF, van Lier P, Verhulst FC. Latent class analysis of anxiety and depressive symptoms in referred adolescents. $J$ Affect Disord. 2005;88(3):299-306.

69. Burstein M, Georgiades K, Lamers F, Swanson SA, Cui L, He JP, Avenevoli S, Merikangas KR. Empirically derived subtypes of lifetime anxiety disorders: developmental and clinical correlates in U.S. adolescents. J Consult Clin Psychol. 2012;80(1):102-115.

70. Lamers F, Burstein M, He JP, Avenevoli S, Angst J, Merikangas KR. Structure of major depressive disorder in adolescents and adults in the US general population.

Br J Psychiatry. 2012;201:143-150.

71. Neuman RJ, Heath A, Reich W, Bucholz KK, Madden PAF, Sun L, Todd RD, Hudziak JJ. Latent class analysis of ADHD and comorbid symptoms in a population sample of adolescent female twins. J Child Psychol Psychiatry. 2001;42(7):933-942.

72. Lewinsohn PM, Rohde P, Seeley JR. Adolescent psychopathology: III. The clinical consequences of comorbidity. J Am Acad Child Adolesc Psychiatry. 1995;34(4):510-519.

73. Fombonne E, Wostear G, Cooper V, Harrington R, Rutter M. The Maudsley longterm follow-up of child and adolescent depression. 2. Suicidality, criminality and social dysfunction in adulthood. Br J Psychiatry. 2001;179:218-223.

74. Wahlstedt C, Thorell LB, Bohlin G. Heterogeneity in ADHD: neuropsychological pathways, comorbidity and symptom domains. J Abnorm Child Psychol. 2009;37(4):551-564.

75. Sanders DH, Illback RJ, Crabtree L, Sanders D. Kentucky Incentives for Prevention 2012: Kentucky Cabinet for Health and Family Services, Department for Behavioral Health, Developmental and Intellectual Disabilities, Division of Behavioral Health; 2012.

76. Kolenikov S, Angeles G. The Use of Discrete Data in PCA: Theory, Simulations, and Applications to Socioeconomic Indices.

http://www.cpc.unc.edu/measure/publications/wp-04-85. Accessed November 7, 2013. 
77. Stata Statistical Software: Release 12. Version 12. College Station, TX: StataCorp LP; 2011.

78. Hu L, Bentler PM. Cutoff criteria for fit indices in covariance structure analysis: conventional criteria versus new alternatives. Struct Equ Modeling. 1999;6(1):155.

79. Flora DB, Curran PJ. An empirical evaluation of alternative methods of estimation for confirmatory factor analysis with ordinal data. Psychol Methods. 2004;9(4):466-491.

80. Muthén LK, Muthén B. Mplus user's guide (1998-2012). Los Angeles, CA: Muthén and Muthén 2012.

81. Nylund K, Asparouhov T, Muthén B. Deciding on the number of classes in latent class analysis and growth mixture modeling: a Monte Carlo simulation study. . Struct Equ Modeling. 2007;14(4):535-569.

82. Drapeau A, Beaulieu-Prevost D, Marchand A, Boyer R, Preville M, Kairouz S. A life-course and time perspective on the construct validity of psychological distress in women and men. Measurement invariance of the $\mathrm{K} 6$ across gender. BMC Med Res Methodol. 2010;10:68.

83. Unick GJ, Snowden L, Hastings J. Heterogeneity in comorbidity between major depressive disorder and generalized anxiety disorder and its clinical consequences. J Nerv Ment Dis. 2009;197(4):215-224.

84. Peiper N, Rodu B. Evidence of sex differences in the relationship between current tobacco use and past-year serious psychological distress: 2005-2008 National Survey on Drug Use and Health. Soc Psychiatry Psychiatr Epidemiol. 2013;48(8):1261-1271.

85. Kessler RC, Berglund P, Demler O, Jin R, Koretz D, Merikangas KR, Rush AJ, Walters EE, Wang PS. The epidemiology of major depressive disorder: results from the National Comorbidity Survey Replication (NCS-R). JAMA. 2003;289(23):3095-3105.

86. Merikangas K, Avenevoli S, Costello J, Koretz D, Kessler RC. National comorbidity survey replication adolescent supplement (NCS-A): I. Background and measures. J Am Acad Child Adolesc Psychiatry. 2009;48(4):367-369.

87. Kessler RC, Avenevoli S, Costello EJ, Green JG, Gruber MJ, Heeringa S, Merikangas KR, Pennell BE, Sampson NA, Zaslavsky AM. National comorbidity survey replication adolescent supplement (NCS-A): II. Overview and design. $J$ Am Acad Child Adolesc Psychiatry. 2009;48(4):380-385.

88. Prochaska JJ, Sung HY, Max W, Shi Y, Ong M. Validity study of the K6 scale as a measure of moderate mental distress based on mental health treatment need and utilization. Int J Methods Psychiatr Res. 2012;21(2):88-97.

89. Furukawa TA, Kessler RC, Slade T, Andrews G. The performance of the K6 and K10 screening scales for psychological distress in the Australian National Survey of Mental Health and Well-Being. Psychol Med. 2003;33(2):357-362.

90. Furukawa TA, Kawakami N, Saitoh M, Ono Y, Nakane Y, Nakamura Y, Tachimori H, Iwata N, Uda H, Nakane H, Watanabe M, Naganuma Y, Hata Y, Kobayashi M, Miyake Y, Takeshima T, Kikkawa T. The performance of the Japanese version of the K6 and K10 in the World Mental Health Survey Japan. Int J Methods Psychiatr Res. 2008;17(3):152-158. 
91. Green JG, McLaughlin KA, Alegria M, Costello EJ, Gruber MJ, Hoagwood K, Leaf PJ, Olin S, Sampson NA, Kessler RC. School mental health resources and adolescent mental health service use. J Am Acad Child Adolesc Psychiatry. 2013;52(5):501-510.

92. Dowdy E, Ritchey K, Kamphaus RW. School-Based Screening: A PopulationBased Approach to Inform and Monitor Children's Mental Health Needs. School Ment Health. 2010;2(4):166-176.

93. Cohen P, Hesselbart CS. Demographic factors in the use of children's mental health services. Am J Public Health. 1993;83(1):49-52.

94. Slade EP. The relationship between school characteristics and the availability of mental health and related health services in middle and high schools in the United States. J Behav Health Serv Res. 2003;30(4):382-392.

95. Sanders DH, Illback RJ, Crabtree L, Sanders D. Kentucky Incentives for Prevention: State and Regional Data Report - 30-Day Use Among 10th Graders: Kentucky Cabinet for Health and Family Services, Department for Behavioral Health, Developmental and Intellectual Disabilities, Division of Behavioral Health; 2013.

96. Harald B, Gordon P. Meta-review of depressive subtyping models. J Affect Disord. 2012;139(2):126-140.

97. Quitkin FM, Stewart JW, McGrath PJ, Liebowitz MR, Harrison WM, Tricamo E, Klein DF, Rabkin JG, Markowitz JS, Wager SG. Phenelzine versus imipramine in the treatment of probable atypical depression: defining syndrome boundaries of selective MAOI responders. Am J Psychiatry. 1988;145(3):306-311.

98. March J, Silva S, Vitiello B, Team T. The Treatment for Adolescents with Depression Study (TADS): methods and message at 12 weeks. J Am Acad Child Adolesc Psychiatry. 2006;45(12):1393-1403.

99. Lewinsohn PM, Allen NB, Seeley JR, Gotlib IH. First onset versus recurrence of depression: differential processes of psychosocial risk. J Abnorm Psychol. 1999;108(3):483-489.

100. Rao U, Hammen C, Daley SE. Continuity of depression during the transition to adulthood: a 5-year longitudinal study of young women. $J$ Am Acad Child Adolesc Psychiatry. 1999;38(7):908-915.

101. Neil AL, Christensen H. Efficacy and effectiveness of school-based prevention and early intervention programs for anxiety. Clin Psychol Rev. 2009;29(3):208215.

102. McGorry PD, Purcell R, Hickie IB, Yung AR, Pantelis C, Jackson HJ. Clinical staging: a heuristic model for psychiatry and youth mental health. Med J Aust. 2007;187(7 Suppl):S40-42.

103. Angst J, Gamma A, Benazzi F, Ajdacic V, Rossler W. Melancholia and atypical depression in the Zurich study: epidemiology, clinical characteristics, course, comorbidity and personality. Acta Psychiatr Scand Suppl. 2007(433):72-84.

104. Lewinsohn PM, Pettit JW, Joiner TE, Jr., Seeley JR. The symptomatic expression of major depressive disorder in adolescents and young adults. J Abnorm Psychol. 2003;112(2):244-252. 
105. Nandi A, Beard JR, Galea S. Epidemiologic heterogeneity of common mood and anxiety disorders over the lifecourse in the general population: a systematic review. BMC Psychiatry. 2009;9:31. 


\section{Appendix 1}

$\underline{\text { DSM-IV Major Depressive Episode and Major Depressive Disorder Criteria }}^{31}$

Depressed mood and/or loss of interest or pleasure in life activities for at least 2 weeks and at least five of the following symptoms that cause clinically significant impairment in social, work, or other important areas of functioning almost every day:

1. Depressed mood most of the day.

2. Diminished interest or pleasure in all or most activities.

3. Significant unintentional weight loss or gain.

4. Insomnia or sleeping too much.

5. Agitation or psychomotor retardation noticed by others.

6. Fatigue or loss of energy.

7. Feelings of worthlessness or excessive guilt.

8. Diminished ability to think or concentrate, or indecisiveness.

9. Recurrent thoughts of death. 
Appendix 2

DSM-IV Dysthymic Disorder Criteria $^{31}$

Depressed mood most of the day for more days than not, for at least 2 years, and the presence of two or more of the following symptoms that cause clinically significant impairment in social, work, or other important areas of functioning:

1. Poor appetite or overeating.

2. Insomnia or sleeping too much.

3. Low energy or fatigue.

4. Low self-esteem.

5. Poor concentration or difficulty making decisions.

6. Feelings of hopelessness. 


\section{Appendix 3}

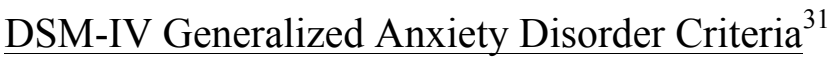

Excessive anxiety and worry (apprehensive expectation), occurring more days than not for at least 6 months, about a number of events or activities (such as work or school performance), and the presence of three or more (one in children) of the following six symptoms:

1. Restlessness or feeling keyed up or on edge.

2. Being easily fatigued.

3. Difficulty concentrating or mind going blank.

4. Irritability.

5. Muscle tension.

6. Sleep disturbance (difficulty falling or staying asleep, or restless unsatisfying sleep). 
Appendix 4

$\underline{\text { DSM-IV Panic Attack Criteria }}^{31}$

A discrete period of intense fear or discomfort, in which four or more of the following symptoms developed abruptly and reached a peak within ten minutes:

1. Palpitations, pounding heart or accelerated heart rate.

2. Sweating.

3. Trembling or shaking.

4. Sensations of shortness of breath or smothering.

5. Feeling of choking.

6. Chest pain or discomfort.

7. Nausea or abdominal distress.

8. Feeling dizzy, unsteady, light headed or faint.

9. Derealization (feelings of unreality) or depersonalization (being detached from oneself).

10. Fear of losing control or going crazy.

11. Fear of dying.

12. Paresthesias (numbness or tingling sensations).

13. Chills or hot flushes. 
Appendix 5

\section{$\underline{\text { DSM-IV Specific Phobia Criteria }}^{31}$}

1. Marked and persistent fear that is excessive or unreasonable, cued by the presence or anticipation of a specific object or situation (e.g. flying, heights, animals, receiving an injection, seeing blood).

2. Exposure to the phobic stimulus almost invariably provokes an immediate anxiety response, which may take the form of a situationally bound or situationally predisposed panic attack. In children, the anxiety may be expressed by crying, tantrums, freezing, or clinging.

3. The person recognizes that the fear is excessive and unreasonable. In children this feature may be absent.

4. The phobic situation is avoided or is endured with intense anxiety or distress.

5. The avoidance, anxious anticipation, or distress in the feared situation(s) interferes significantly with a person's routine, occupational (or academic) functioning, or social activities or relationships or there is a marked distress about having the phobia.

6. In individuals under the age of 18 years the duration is at least 6 months.

7. The anxiety panic attacks or phobic avoidance associated with the specific object or situation are not better accounted for by another mental disorder such as OCD (e.g. fear of dirt in someone with an obsession about contamination), post traumatic stress disorder (e.g. avoidance of school), social phobia, panic disorder with agoraphobia or agoraphobia without history of panic disorder). 
Appendix 6

\section{$\underline{\text { DSM-IV Social Phobia Criteria }}^{31}$}

1. Marked and persistent fear of one or more social or performance situations in which the person is exposed to unfamiliar people or to possible scrutiny by others. The individual fears that he or she will act in a way (or show anxiety symptoms) that will be humiliating or embarrassing. In children, there must be evidence of the capacity for age-appropriate social relationships with familiar people and the anxiety must occur in peer settings, not just interactions with adults.

2. Exposure to the feared social situation almost invariably provokes anxiety, which may take the form of a situationally bound or situationally predisposed Panic Attack. In children, the anxiety may be expressed by crying, tantrums, freezing, or shrinking from social situations with unfamiliar people.

3. The person recognizes that the fear is excessive or unreasonable. In children, this feature may be absent.

4. The feared social or performance situations are avoided or else are endured with intense anxiety or distress.

5. The avoidance, anxious anticipation, or distress in the feared social or performance situation interferes significantly with the person's normal routine, occupational or academic functioning, or social activities or relationships, or there is marked distress about having the phobia. 
Appendix 7

DSM-IV Substance Abuse Disorder Criteria ${ }^{31}$

Maladaptive pattern of substance use leading to clinically significant impairment or distress as manifested by one or more of the following, occurring within a 12-month period:

1. Recurrent failure to fulfill major role obligations at work, school, or home.

2. Recurrent substance use in situations in which it is physically hazardous

3. Recurrent substance-related legal problems

4. Continued substance use despite having persistent or recurrent social or interpersonal problems caused or exacerbated by the effects of the substance. 
Appendix 8

\section{DSM-IV Substance Dependence Disorder Criteria $^{31}$}

Maladaptive pattern of substance use leading to clinically significant impairment or distress, as manifested by three or more of the following, occurring any time in the same 12-month period:

1. Tolerance, as defined by either of the following:

a. Need for markedly increased amounts of the substance to achieve intoxication or the desired effect or

b. Markedly diminished effect with continued use of the same amount of the substance.

2. Withdrawal, as manifested by either of the following:

a. The characteristic withdrawal syndrome for the substance or

b. The same (or closely related) substance is taken to relieve or avoid withdrawal symptoms.

3. The substance is often taken in larger amounts or over a longer period than intended.

4. There is a persistent desire or unsuccessful efforts to cut down or control substance use.

5. A great deal of time is spent in activities necessary to obtain the substance, use the substance, or recover from its effects.

6. Important social, occupational, or recreational activities are given up or reduced because of substance use.

7. The substance use is continued despite knowledge of having a persistent physical or psychological problem that is likely to have been caused or exacerbated by the substance. 
Appendix 9

\section{DSM-IV Conduct Disorder Criteria $^{31}$}

A repetitive and persistent pattern of behavior in which the basic rights of others or major age-appropriate societal norms or rules are violated, as manifested by the presence of three or more of the following criteria in the past 12 months, with at least one criterion present in the past 6 months:

Aggression to people and animals:

1. Often bullies, threatens, or intimidates others.

2. Often initiates physical fights.

3. Has used a weapon that can cause serious physical harm to others.

4. Has been physically cruel to people.

5. Has been physically cruel to animals.

6. Has stolen while confronting a victim.

7. Has forced someone into sexual activity

Destruction of property:

8. Has deliberately engaged in fire setting with the intention of causing serious damage.

9. Has deliberately destroyed others' property (other than by fire setting).

Deceitfulness or theft:

10. Has broken into someone else's house, building, or car.

11. Often lies to obtain goods or favors or to avoid obligations.

12. Has stolen items of nontrivial value without confronting a victim.

Serious violations of rules:

13. Often stays out at night despite parental prohibitions, beginning before age 13 years.

14. Has run away from home overnight at least twice while living in parental or parental surrogate home (or once without returning for a lengthy period).

15. Is often truant from school, beginning before age 13 years. 
Appendix 10

\section{DSM-IV Oppositional Defiant Disorder Criteria ${ }^{31}$}

A pattern of negativistic, hostile, and defiant behavior lasting at least 6 months, during which four or more of the following are present:

1. Often loses temper.

2. Often argues with adults.

3. Often actively defies or refuses to comply with adults' requests or rules.

4. Often deliberately annoys people.

5. Often blames others for his or her mistakes or misbehavior.

6. Often touchy or easily annoyed by others.

7. Often angry and resentful.

8. Often spiteful or vindictive 
Appendix 11

$\underline{\text { DSM-IV Attention Deficit Hyperactivity Disorder Criteria }}{ }^{31}$

Either 1 or 2:

1. Six or more of the following symptoms of inattention have persisted for at least six months to a degree that is maladaptive and inconsistent with developmental level:

a. Often fails to give close attention to details or makes careless mistakes in schoolwork, work, or other activities.

b. Often has difficulty sustaining attention to tasks or play activities.

c. Often does not seem to listen when spoken to directly.

d. Often does not follow through on instructions and fails to finish schoolwork, chores, or duties in the workplace (not due to oppositional behavior or failure to understand instructions).

e. Often has difficulty organizing tasks and activities.

f. Often avoids, dislikes, or is reluctant to engage in tasks that require sustained mental effort (such as school work or homework).

g. Often loses things necessary for tasks or activities (e.g., toys, school assignments, pencils, books, or tools).

h. Is often easily distracted by extraneous stimuli.

i. Is often forgetful in daily activities.

2. Six or more of the following symptoms of hyperactivity-impulsivity have persisted for at least six months to a degree that is maladaptive and inconsistent with developmental level:

Hyperactivity:

a. Often fidgets with hands or feet or squirms in seat.

b. Often leaves seat in classroom or in other situations in which remaining seated is required.

c. Often runs about or climbs excessively in situations in which it is inappropriate (in adolescents or adults, may be limited to subjective feelings of restlessness).

d. Often has difficulty playing or engaging in leisure activities quietly.

e. Is often "on the go," or often acts as if "driven by a motor."

f. Often talks excessively

Impulsivity:

g. Often blurts out answers before questions have been completed.

h. Often has difficulty awaiting turn.

i. Often interrupts or intrudes on others (e.g., butts into conversations or games). 
Appendix 12

Final Model Specification for the Confirmatory Factor Analysis

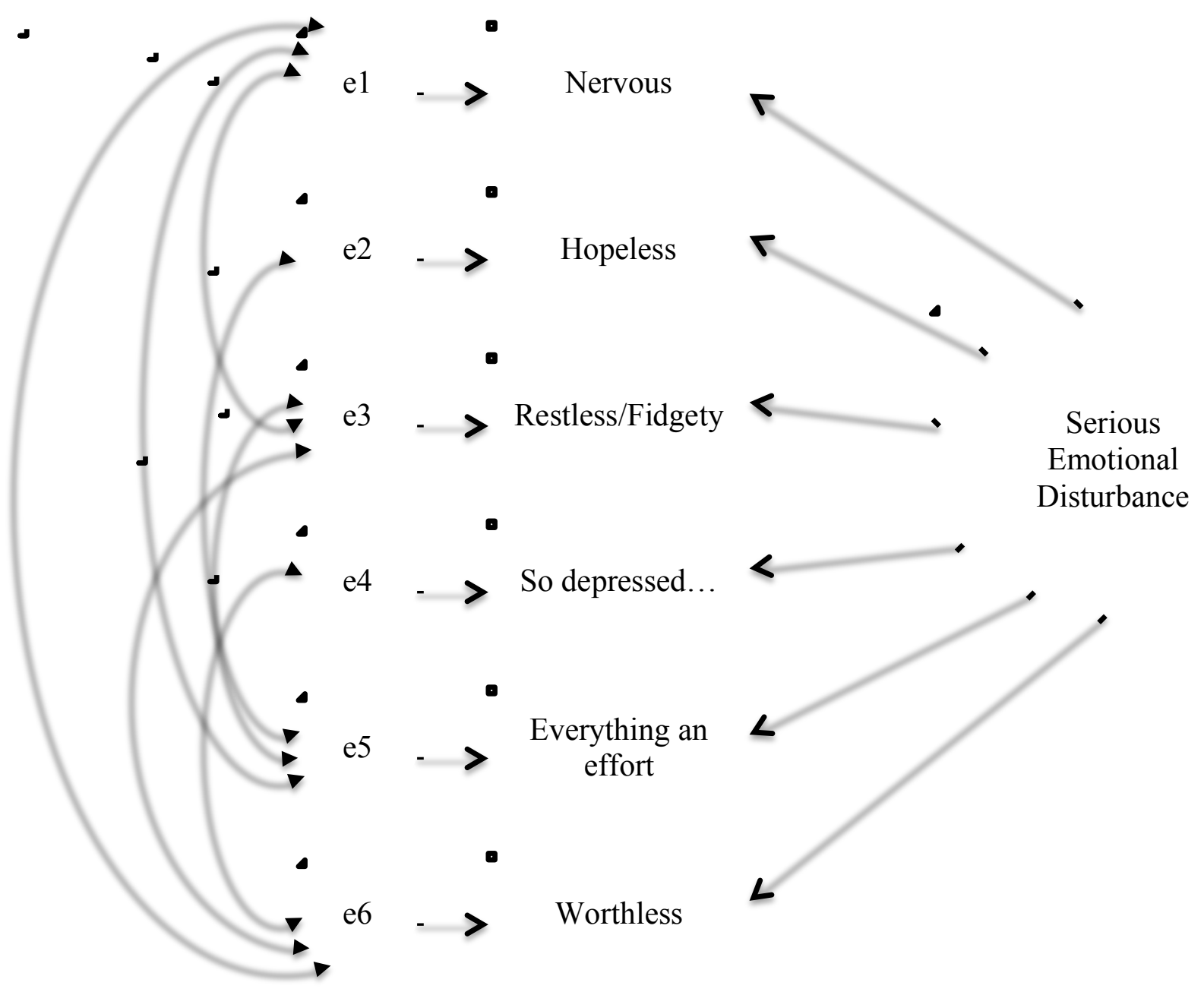




\section{CURRICULUM VITAE}

\section{PERSONAL}

Name:

Nicholas Chalmer Peiper

Birthdate:

July 7, 1982

Address:

Department of Epidemiology \& Population Health School of Public Health \& Information Sciences University of Louisville 485 East Gray Street

Louisville, KY 40202

Telephone:

$502-502-7718$

Fax:

$502-589-1582$

E-mail:

ncpeip01@1ouisville.edu

\section{EDUCATION}

BA Psychology Transylvania University, Lexington, KY (2004)

MPH Health Behavior University of Kentucky, Lexington, KY (2006)

PhD Epidemiology University of Louisville, Louisville, KY (2013)

\section{AREAS OF SPECIALIZATION}

General: Epidemiology, Behavioral Sciences, Clinical Research, Neurobiology Substantive: Addiction Medicine, Social and Psychiatric Epidemiology, Chronic Disease Epidemiology

\section{PROFESSIONAL EXPERIENCE}

Lab Technician, College of Pharmacy, University of Kentucky, Lexington, Kentucky, September 2003-February 2004

Graduate Research Assistant, Kentucky Center for Smoke-Free Policy, College of Nursing, University of Kentucky, Lexington, Kentucky, June 2005-August 2006 
Clinical Trials Coordinator, James Graham Brown Cancer Center, University of Louisville, Louisville, Kentucky, January 2007-September 2008

Graduate Research Assistant, Department of Epidemiology and Population Health, School of Public Health and Information Sciences, University of Louisville, Louisville, Kentucky, September 2008-December 2010

Epidemiologist and Evaluation Researcher, Kentucky Strategic Prevention Enhancement Policy Consortium, Substance Abuse Prevention Program, Division of Behavioral Health, Department for Behavioral Health, Developmental and Intellectual Disabilities, Kentucky Cabinet for Health and Family Services, Frankfort, Kentucky, September 2011-September 2012

Doctoral Candidate, Department of Epidemiology and Population Health, School of Public Health and Information Sciences, University of Louisville, Louisville, Kentucky, October 2011-present

Epidemiologist, REACH Evaluation, Louisville, Kentucky, December 2010present

Epidemiologist and Project Director, State Epidemiologic Outcomes Workgroup, Division of Behavioral Health, Department for Behavioral Health, Developmental and Intellectual Disabilities, Kentucky Cabinet for Health and Family Services, Frankfort, Kentucky, January 2011-present

Epidemiologist and Evaluation Researcher, Partnerships for Success II, Division of Behavioral Health, Department for Behavioral Health, Developmental and Intellectual Disabilities, Kentucky Cabinet for Health and Family Services, Frankfort, Kentucky, January 2013-present

\section{ADDITIONAL SERVICE}

Chair, Lunch and Learn Seminar Series, Department of Epidemiology and Population Health, School of Public Health and Information Sciences, University of Louisville, January 2010-May 2010.

MPH Practicum Preceptor: Robin Weiss, Department of Health Promotion and Behavioral Sciences, School of Public Health and Information Sciences, University of Louisville, Completed May 2012.

MPH Practicum Preceptor: Monica Panwar, Department of Epidemiology and Population Health, School of Public Health and Information Sciences, University of Louisville, Completed May 2013. 
Chair, Kentucky State Epidemiologic Outcomes Workgroup Scientific

Subcommittee, Division of Behavioral Health, Cabinet for Health and Family

Services, Frankfort, Kentucky, January 2013-present.

Member, Substance Abuse Prevention Branch Expert Committee, Division of Behavioral Health, Cabinet for Health and Family Services, Frankfort, Kentucky, March 2013-present.

Co-Chair, EpiHour Seminar Series, Department of Epidemiology and Population Health, School of Public Health and Information Sciences, University of Louisville, July 2013-present.

Member, D.A.R.E. America Scientific Advisory Board, Los Angeles, California, July 2013-present.

\section{FUNDED RESEARCH}

Project Director, September 2010-October 2012, "State Epidemiologic Outcomes Workgroup." Contract HHSS28320070048I/HHSS28300001T, Center for Substance Abuse Prevention, Substance Abuse and Mental Health Services Administration, $\$ 3,000,000$, C.R. Smith, Chair.

Epidemiologist and Evaluation Researcher, September 2011-September 2012, "Strategic Prevention Framework State Prevention Enhancement Grant." Grant SP018628-01, Center for Substance Abuse Prevention, Substance Abuse and Mental Health Services Administration, \$599,892, C.R. Smith, Chair.

Epidemiologist and Evaluation Researcher, September 2011-October 2014, "Cooperative Agreements for State-Sponsored Youth Suicide Prevention and Early Detection." Grant SM060449-01, Center for Mental Health Services, Substance Abuse and Mental Health Services Administration, $\$ 480,000$, J. Ulrich, Program Director.

Epidemiologist and Evaluation Researcher, September 2012-October 2015, "Strategic Prevention Framework Partnership for Success II." Grant SP01943601, Center for Substance Abuse Prevention, Substance Abuse and Mental Health Services Administration, \$2,674,187, C.R. Smith, Chair.

Project Director and Epidemiologist, September 2013-October 2015, "Strategic Prevention Framework Partnership for Success II SEOW Supplement." Grant SP-13-007, Center for Substance Abuse Prevention, Substance Abuse and Mental Health Services Administration, $\$ 348,000$, C.R. Smith, Chair.

\section{HONORS AND AWARDS}

Founder's Scholarship Recipient, Transylvania University, 2000-2004 
Dean's List, Transylvania University, Spring 2004

Enhancement Scholarship Recipient, University of Kentucky College of Public Health 2005-2006

Dean's List, University of Kentucky College of Public Health, 2005-2006

Magna Cum Laude, University of Kentucky College of Public Health, 2004-2006

Summa Cum Laude, University of Louisville School of Public Health and Information Sciences, 2008-present

Golden Key International Honour Society, University of Louisville, 2009

\section{PROFESSIONAL AFFILIATIONS}

$\begin{array}{ll}2007 & \text { American Psychological Association } \\ 2008 & \text { American Public Health Association } \\ 2009 & \text { Society for Epidemiologic Research } \\ 2009 & \text { American College of Epidemiology } \\ 2012 & \text { Society for Prevention Research }\end{array}$

\section{RESEARCH AND SCHOLARLY PRODUCTIVITY}

Peiper N. Emphasizing Culture and Race in Treatment (ECRT) Model, University of Kentucky College of Public Health Capstone, High Pass, July 2006.

Peiper N. The Performance of the K6 Scale in a Large Adolescent Sample, University of Louisville School of Public Health and Information Sciences, Dissertation Defense, Unanimous Pass, December 2013.

\section{Posters and Presentations}

Peiper N. Using Community Data in the Implementation and Evaluation of Tobacco Policies, Kentucky Public Health Association Annual Meeting, Louisville, KY, March 2006.

Maggio L, Budd L, Peiper N, et al. Secondhand Smoke Exposure at the Capitol Annex, May 2006. 
Peiper N, Stone R, van Zyl, R, Rodu B. Tobacco Risk Perceptions Among a Sample of Full-time University Faculty, Research!Louisville, Louisville, KY, October 2008.

Patel D, Peiper N, Rodu B. Perceptions of the Health Risks Related to Cigarettes and Nicotine Among University Faculty, Research!Louisville, Louisville, KY, October 2010.

Peiper N, Hornung C. Quality of Life Outcomes Among Heart Failure Patients Who Smoke, Research!Louisville, Louisville, KY, October 2010.

Peiper N. Kentucky State Epidemiologic Workgroup: Substance Abuse and Mental Health, Kentucky Department for Public Health Data Workgroup, Frankfort, KY, March 2011.

Donneyong M, Peiper N, Hornung C. Quality of Life in Heart Failure Patients: A Structural Equation Model, Congress of Epidemiology, Montreal, Quebec, Canada, June 2011.

Peiper N, Donneyong M, Hornung C. Quality of Life Outcomes Among Heart Failure Patients Who Smoke, Congress of Epidemiology, Montreal, Quebec, Canada, June 2011.

Peiper N. The Insular Cortex and Cigarette Smoking, Department of Epidemiology and Population Health, School of Public Health and Information Sciences, University of Louisville, Louisville, Kentucky, October 2011.

Peiper N. Findings from the Kentucky State Epidemiologic Outcomes Workgroup, State Epidemiologic Outcomes Workgroup Workshop, Substance Abuse and Mental Health Services Administration, Gaithersburg, Maryland, December 2011

Peiper N. Prescription Drug Abuse in Kentucky, Center for the Application of Prevention Technologies Regional Technical Expert Panel, Substance Abuse and Mental Health Services Administration, March 2012.

Peiper N. Kentucky Data Warehouse Training, Regional Prevention Center Director's Meeting, Elizabethtown, Kentucky, April 2013.

Peiper N, Drashner N, Kasat S. State and Community Surveillance of Adolescent Serious Emotional Disturbance, National Prevention Network, Oklahoma City, Oklahoma, August 2013.

Peiper N, Clark P, Birkby B, Ulrich J. Subtypes of Bullying and Suicide Behaviors Across Kentucky High School Students, American College of Epidemiology, Louisville, Kentucky, September 2013.

Peiper N. Partnerships for Success II: State and Regional Projections for Prescription Drug Abuse and Underage Drinking, Regional Prevention Center Directors' Summit, Dale Hollow State Park, Kentucky, October 2013. 


\section{Articles in Peer-Reviewed Journals}

Lee K, Hahn E, Peiper N, et al. Differential impacts of smoke-free laws on indoor air quality. Journal of Environmental Health 2008, 70(8): 24-30.

Peiper N, Stone R, van Zyl R, Rodu B. University faculty perceptions of the health risks related to cigarettes and smokeless tobacco. Drug \& Alcohol Review 2010, 29(2): 12130 .

Rodu B, Peiper N, Cole P. Acute myocardial infarction mortality before and after statewide smoking bans. Journal of Community Health 2011, 37(2): 468-72.

Patel D, Peiper N, Rodu B. Perceptions of the health risks related to cigarettes and nicotine among university faculty. Addiction Research \& Theory 2013, 21(2).

Peiper N, Rodu B. Evidence of sex differences in the relationship between current tobacco use and past-year serious psychological distress: 2005-2008 National Survey on Drug Use and Health. Social Psychiatry \& Psychiatric Epidemiology 2013, 48(8): 12611271.

Peiper N, Pennington M, Sanders D, et al. Health access nurturing development services: population-based effectiveness in an impoverished, rural state. Under review.

Peiper N, Baumgartner R. Evidence of serum antioxidant vitamin deficiencies among adult men and women with major depressive disorder: Results from the 2005-2006 National Health and Nutrition Examination Survey. Under review.

Peiper N, Crabtree L, Clayton R, et al. Epidemiologic trends of adolescent prescription drug abuse in Kentucky. Under review.

Peiper N, Clark P, Birkby B, Ulrich J. Subtypes of bullying and suicide behavior across Kentucky high school students. Under review.

Peiper N, Clayton R, Wilson R, Illback R. Mental health promotion and policy: increasing data-driven capacity at the regional level. Pending submission.

\section{Technical Reports}

Hahn E, Lee K, Robertson H, Vogel S, Lee S, Peiper N, Powell R, Troutman A. Indoor air quality in Louisville: did passage of a comprehensive smoke-free ordinance clear the air? University of Kentucky, Colleges of Nursing and Public Health, February 2008.

Peiper $\mathbf{N}$ et al. Preventing substance abuse and mental illness in Kentucky: a state profile to promote positive mental and behavioral health. Technical report commissioned by the State Epidemiologic Outcomes Workgroup for the Center for Substance Abuse 
Prevention at the Substance Abuse and Mental Health Services Administration, 60 pages, May 2011.

Peiper $\mathbf{N}$ et al. Preventing substance abuse and mental illness in Kentucky: a community profile of Eastern Kentucky. Technical report commissioned by the State Epidemiologic Outcomes Workgroup for the Center for Substance Abuse Prevention at the Substance Abuse and Mental Health Services Administration, 30 pages, June 2011.

Illback R, Peiper N, Sanders D, et al. Birth outcomes of participants in Kentucky's HANDS home visitation program: a follow-up study comparing matched and unmatched high-risk groups. Technical report commissioned by the Home Visiting Evidence of Effectiveness Review at the Department for Health and Human Services, 19 pages, July 2011.

Peiper $\mathbf{N}$ et al. Prescription drug trends in Kentucky. Technical report commissioned by the State Epidemiologic Outcomes Workgroup for the Center for Substance Abuse Prevention at the Substance Abuse and Mental Health Services Administration, 17 pages, December 2011.

Peiper $\mathbf{N}$ et al. Preventing substance abuse and mental illness in Kentucky: 2012 state profile. Technical report commissioned by the State Epidemiologic Outcomes Workgroup for the Center for Substance Abuse Prevention at the Substance Abuse and Mental Health Services Administration, 46 pages, March 2012.

Peiper $\mathbf{N}$ et al. Preventing substance abuse and mental illness in Kentucky: a community profile of Western Kentucky. Technical report commissioned by the State Epidemiologic Outcomes Workgroup for the Center for Substance Abuse Prevention at the Substance Abuse and Mental Health Services Administration, 32 pages, May 2012.

Pennington M, Peiper N. Perinatal Depression: Engagement of At-Risk Women in Mental Health Services. Technical report commissioned by the Louisville Metro Healthy Start Program, Louisville Metro Department of Public Health and Wellness, Louisville, Kentucky, 16 pages, December 2012.

Clayton R, Illback R, Peiper N. Economic Evaluation of the Jigsaw Model: An Analysis of the Global Burden of Mental Ill-Health Among Young People, the Cost to Government, and an Economic Justification of the Jigsaw Model of Early Intervention and Prevention. Technical report commissioned by Headstrong - The National Centre for Youth Mental Health, Dublin, Ireland, 113 pages, December 2012.

Birkby B, Luther E, Peiper N. KIDS NOW Plus Fiscal Year 2012 Annual Report. Technical report commissioned by the Division of Behavioral Health at the Cabinet for Health and Family Services, Frankfort, Kentucky, 27 pages, December 2012.

Peiper N, Smith P, Pennington M. Regional trends of underage drinking in the Adanta region: results from the 2010 Kentucky Incentives for Prevention. Technical report 
commissioned by the State Epidemiologic Outcomes Workgroup for the Center for Substance Abuse Prevention at the Substance Abuse and Mental Health Services Administration, 12 pages, January 2013.

Peiper N, Smith P, Pennington M. Regional trends of underage drinking in the Bluegrass region: results from the 2010 Kentucky Incentives for Prevention. Technical report commissioned by the State Epidemiologic Outcomes Workgroup for the Center for Substance Abuse Prevention at the Substance Abuse and Mental Health Services Administration, 12 pages, January 2013.

Peiper N, Smith P, Pennington M. Regional trends of underage drinking in the Communicare region: results from the 2010 Kentucky Incentives for Prevention. Technical report commissioned by the State Epidemiologic Outcomes Workgroup for the Center for Substance Abuse Prevention at the Substance Abuse and Mental Health Services Administration, 12 pages, January 2013.

Peiper N, Smith P, Pennington M. Regional trends of underage drinking in the KIPDA region: results from the 2010 Kentucky Incentives for Prevention. Technical report commissioned by the State Epidemiologic Outcomes Workgroup for the Center for Substance Abuse Prevention at the Substance Abuse and Mental Health Services Administration, 12 pages, January 2013.

Peiper N, Smith P, Pennington M. Regional trends of adolescent prescription drug abuse in the Communicare region: results from the 2010 Kentucky Incentives for Prevention. Technical report commissioned by the State Epidemiologic Outcomes Workgroup for the Center for Substance Abuse Prevention at the Substance Abuse and Mental Health Services Administration, 12 pages, January 2013.

Peiper N, Smith P, Pennington M. Regional trends of adolescent prescription drug abuse in the Lifeskills region: results from the 2010 Kentucky Incentives for Prevention. Technical report commissioned by the State Epidemiologic Outcomes Workgroup for the Center for Substance Abuse Prevention at the Substance Abuse and Mental Health Services Administration, 12 pages, January 2013.

Peiper N, Smith P, Pennington M. Regional trends of adolescent prescription drug abuse in the Pennyroyal region: results from the 2010 Kentucky Incentives for Prevention. Technical report commissioned by the State Epidemiologic Outcomes Workgroup for the Center for Substance Abuse Prevention at the Substance Abuse and Mental Health Services Administration, 12 pages, January 2013.

Peiper N, Smith P, Pennington M. Regional trends of adolescent prescription drug abuse in the River Valley region: results from the 2010 Kentucky Incentives for Prevention. Technical report commissioned by the State Epidemiologic Outcomes Workgroup for the Center for Substance Abuse Prevention at the Substance Abuse and Mental Health Services Administration, 12 pages, January 2013. 
Peiper N, Luther E, Pennington M. Attitudes and perceptions surrounding tobacco use, smoke-free ordinances, and secondhand smoke: a community survey of adults in Breckinridge County. Technical report commissioned by the Breckinridge County Health Department and the Breckinridge County Coalition for Change, 16 pages, February 2013.

Peiper $\mathbf{N}$ et al. Adolescent alcohol abuse in Kentucky. Technical report commissioned by the State Epidemiologic Outcomes Workgroup for the Center for Substance Abuse Prevention at the Substance Abuse and Mental Health Services Administration, 16 pages, July 2013.

Peiper N, Birkby B. Suicide Prevention Efforts for Adolescents in Kentucky: A Report of Collaborative Activities Among Agencies in Communicare. Technical report commissioned by the Suicide Prevention Efforts for Adolescents in Kentucky (SPEAK) in the Division of Behavioral Health at the Cabinet for Health and Family Services, Frankfort, Kentucky, 16 pages, August 2013.

Peiper N, Luther E, Pennington M. Regional trends of underage drinking in the Kentucky River region: results from the 2012 Kentucky Incentives for Prevention. Technical reported commissioned by the Partnerships for Success II for the Division of Behavioral Health at the Cabinet for Health and Family Services, Frankfort, Kentucky, 14 pages, September 2013.

Peiper N, Luther E, Pennington M. Regional trends of underage drinking in the Northkey region: results from the 2012 Kentucky Incentives for Prevention. Technical reported commissioned by the Partnerships for Success II for the Division of Behavioral Health at the Cabinet for Health and Family Services, Frankfort, Kentucky, 14 pages, September 2013.

Peiper N, Luther E, Pennington M. Regional trends of underage drinking in the Pathways region: results from the 2012 Kentucky Incentives for Prevention. Technical reported commissioned by the Partnerships for Success II for the Division of Behavioral Health at the Cabinet for Health and Family Services, Frankfort, Kentucky, 14 pages, September 2013.

Peiper N, Luther E, Pennington M. Regional trends of underage drinking in the Comprehend region: results from the 2012 Kentucky Incentives for Prevention. Technical reported commissioned by the Partnerships for Success II for the Division of Behavioral Health at the Cabinet for Health and Family Services, Frankfort, Kentucky, 14 pages, September 2013.

Peiper N, Luther E, Pennington M. Regional trends of adolescent prescription drug abuse in the Cumberland River region: results from the 2012 Kentucky Incentives for Prevention. Technical reported commissioned by the Partnerships for Success II for the Division of Behavioral Health at the Cabinet for Health and Family Services, Frankfort, Kentucky, 14 pages, September 2013. 
Peiper N, Luther E, Pennington M. Regional trends of adolescent prescription drug abuse in the Kentucky River region: results from the 2012 Kentucky Incentives for Prevention. Technical reported commissioned by the Partnerships for Success II for the Division of Behavioral Health at the Cabinet for Health and Family Services, Frankfort, Kentucky, 14 pages, September 2013.

Peiper N, Pennington M, Illback R. Partnerships for Success II: Underage Drinking in Kentucky. Technical report commissioned by the Partnerships for Success II for the Division of Behavioral Health at the Cabinet for Health and Family Services, Frankfort, Kentucky, 15 pages, November 2013. 